\title{
Políticas educativas en Venezuela (2000-2016): una mirada crítica
}

\author{
Education Policies in Venezuela (2000-2016): A Critical View \\ Políticas educacionais na Venezuela (2000-2016): um olhar crítico
}

Reinaldo Rojas ${ }^{1}$
Universidad Pedagógica Experimental Libertador, Venezuela
Grupo de investigación HISULA - UPTC
José Pascual Mora García ${ }^{2}$
Universidad de Los Andes, Venezuela
Grupo de investigación HISULA - UPTC

Recepción: 08/12/2018

Evaluación: 08/02/2019

Aceptación: 17/02/2019

Artículo de Investigación - Revisión

https://doi.org/10.19053/01227238.9483

\section{RESUMEN}

El presente estudio tiene el propósito de presentar una mirada crítica de las políticas educativas que el Estado venezolano ha puesto en ejecución en el periodo de gobierno del presidente Hugo Chávez Frías (1999-2012) y continuadas por el presidente Nicolás Maduro (2013-2016) en el periodo de la denominada "Revolución Bolivariana" y del "Socialismo del Siglo XXI". En este sentido, hemos abordado el estudio de este proceso político educativo desde las perspectivas de la Historia
Social de la Educación, lo cual nos lleva a ubicar la educación en su contexto social global y en el tiempo histórico de la implantación, desde 1948, del modelo de la educación de masas en el que se inscribe la Constitución de 1999 y orienta el diseño de las políticas públicas en el sector educativo para el lapso de 1999-2016. Para facilitar al lector la comprensión de este proceso, hemos dividido el presente ensayo en dos partes: en la primera se reconstruye brevemente el proceso educativo de

1 Doctor en Historia. Director del Centro de Investigaciones Históricas y Sociales "Federico Brito Figueroa" de la UPEL y miembro del Grupo de Investigación "Historia y prospectiva de la Universidad Latinoamericana” (HISULA). Correo electrónico: reinaldoeneal@ gmail.com

2 Postdoctorando (2018-2019), Universidad Pedagógica y Tecnológica de Colombia. Profesor Titular Emérito de la Universidad de Los Andes, Núcleo "Dr. Pedro Rincón Gutiérrez". Doctor en Historia (USM- Caracas, 2002), Doctor en Pedagogía (URV-Tarragona-España, 2009). Miembro de los Grupos de investigación HISULA e ILAC, adscritos a la UPTC, Centro Internacional VENDIMIA y Coordinador del Grupo HEDURE-ULA-Táchira-Venezuela. Presidente de la red SHELA (2011- 2016). Correo electrónico: pascualmoraster@gmail.com 
1948 a 2010 y la segunda parte se centra en la evaluación de las políticas educativas en el nivel universitario, en especial, en lo que respecta a su impacto sobre una de las misiones de la Universidad como es la investigación científica y la producción de conocimiento.

Palabras clave: Políticas públicas; educación superior; Universidad; Venezuela.

ABSTRACT
The purpose of this study is to present
a critical view of the educational policies
implemented by the Venezuelan State du-
ring the government of President Hugo
Chávez Frías (1999-2012) and continued
by President NicolásMaduro (2013-2016)
within the so-called "Bolivarian Revolu-
tion" and the "Socialism of the 21st Cen-
tury". In this sense, we have approached
the study of this political-educational pro-
cess from the perspectives of the Social
History of Education, which leads us to
situate education in its global social con-
text, since 1948, in the historical time of
the implementation of the model of Mass
Education in which the 1999 Constitution
is inscribed and from which it guides the
design of public policies in the educa-
tion sector during 1999-2016. In order to
facilitate the reader's understanding of
this process, we have divided this essay
into two parts: The first briefly recons-
tructs the educational process from 1948
to 2010 , while the second part focuses on
the evaluation of education policies at the
university level, especially with regard to
their impact on one of the missions of the

University; the scientific research and the production of knowledge.

Keywords: Public policies; higher education; University; Venezuela.

\section{RESUMO}

O presente estudo tem o propósito de apresentar uma perspectiva crítica sobre as políticas educacionais que o Estado venezuelano executou no período do governo do presidente Hugo Chávez Frías (1999-2012) e que foram continuadas pelo presidente Nicolás Maduro (2013-2016) no período da denominada "Revolução Bolivariana" e do "Socialismo do Século XXI". Neste sentido, abordamos o estudo deste processo político educativo a partir das perspectivas da História Social da Educação, que nos leva a situar a educação em seu contexto social global e no tempo histórico da implantação, desde 1948, do modelo de educação de massas em que se inscreve a Constituição de 1999 e orienta a elaboração das políticas públicas no setor educativo para o lapso de 1999-2016. Para facilitar ao leitor a compreensão deste processo, dividimos o presente ensaio em duas partes: na primeira se reconstrói brevemente o processo educativo de 1948 a 2010 e a segunda parte se centra na avaliação das políticas educativas no nível universitário, especialmente no que diz respeito a seu impacto sobre uma das missões da Universidade como é a pesquisa científica e a produção de conhecimento.

Palavras-chave: Políticas públicas; educação superior; Universidade; Venezuela.

\section{INTRODUCCIÓN}

El Sistema de Educación Superior venezolano se constituye formalmente con la aprobación en 1980 de Ley Orgánica de Educación, la cual en su Artículo 28⿳ㅜㅇ define como institutos de educación superior a las universidades, los institutos universitarios pedagógicos, politécnicos, tecnológicos y colegios universitarios, y los institutos de formación de oficiales de las Fuerzas Armadas. Incluye, además, los institutos especiales de formación docente, de bellas artes y de investi- 
gación, así como los institutos superiores de formación de ministros del culto. Es decir, se trata de darle sentido de cuerpo a una serie de instituciones cuyo propósito es la formación profesional y de posgrado, y cuyo origen se remonta a la fundación en 1721 de la Real y Pontificia Universidad de Caracas. ${ }^{3}$

Sin embargo, en el contexto de la Constitución de 1961, el Congreso Nacional había aprobado una Ley de Universidades, publicada en la Gaceta Oficial № 1.429de la República de Venezuela el 8 de septiembre de 1970, en la cual se reconoce la Autonomía comoprincipio rector de la institución universitaria. En ese sentido, la Ley Orgánica de Educación de 1980 tendrá que actuar sobre dos subsistemas de educación superior: el de las Universidades propiamente dichas, formado por universidades autónomas y universidades experimentales ${ }^{4}$, sin autonomía y adscritas al Ministerio de Educación; y el resto de instituciones de formación profesional regidas o supervisadas por el Ministerio de Educación.

Este marco legal, las políticas públicas y las estrategias para el desarrollo de la Educación Superior van a cambiar significativamente con la aprobación en 1999 de la Constitución de la República Bolivariana de Venezuelay,en 2009, con una nueva Ley Orgánica de Educación. Pero más allá de este nuevo contexto jurídico, entre 2000 y 2016 los gobiernos de Hugo Chávez y Nicolás Maduro implantaron una serie de reformas al interior del sistema educativo nacional y construyeron a través de la política de las Misiones Educativas una institucionalidad paralela, cuyos efectos en la formación profesional y en la producción de ciencia y tecnología constituyen el objeto central del presente estudio.

Para una mejor comprensión de este proceso político-social e institucional hemos dividido este análisis en dos partes; en la primera, tratamos de ubicar al lector en el tiempo histórico de la emergencia de la Educación de Masas que se inicia en Venezuela con el gobierno cívico-militar que surge con el Golpe de 1945, donde aparece reflejado en la Constitución de 1947 y en la Ley Orgánica de Educación Nacional de 1948 el principio del Estado Docente, al asumirse por primera vez en el país que la educación es una función esencial del Estado.

En el periodo que va de 1948 a 1980 persiste el principio del Estado Docente pero el sistema educativo entra en crisis a partir de la década de los años 80 ,el impacto del paradigma neoliberal en la década de los 90 termina por generar un alto índice de deserción escolar que superaba el 50\% de la población escolar hasta alcanzar un crecimiento negativo de la matrícula escolar, lo cual se pudo evidenciar hasta 1998. ${ }^{5}$ Esta circunstancia fue generando un debate político, ideológico y doctrinario que trajo cambios en la sociedad venezolana con el emergente modelo implantado por Hugo Chávez. Este escenario es descrito brevemente en el presente artículo, ya que muchas de esas ideas y propuestas forman parte de

3 Al respecto puede consultarse el estudio de Reinaldo Rojas "Historia de la Universidad en Venezuela". Revista Historia de la Educación Latinoamericana, vol. 7, (2005): 73- 98.

4 Para un estudio histórico-institucional de la Universidad Experimental en Venezuela se puede consultar: Reinaldo Rojas. Universidad Centroccidental Lisandro Alvarado. Una historia de 50 años. (Barquisimeto: UCLA, Ediciones del Rectorado 2012), 127.

5 José Pascual Mora García, “La filosofía de Luis Beltrán Prieto Figueroa y su aporte a la historia de la educación actual," EDUCERE, Revista venezolana de Educación. Año XII, no. 42, (2008): 615-625.

http://www.saber.ula.ve/bitstream/123456789/26318/1/articulo21.pdf (Consultado marzo 2017) 
la Agenda Política Educativa que alimentará el debate constituyente de 1999 y donde se afirma el principio del Estado Docente. Lo que sigue a partir del año 2000 es la aplicación de una serie de reformas en el sistema educativo nacional y la implantación como un sistema paralelo de las Misiones Educativas, reformas que son estudiadas desde una perspectiva histórica y critica, centrándonos en la aplicación de esas políticas públicas en el subsistema de educación superior, ahora denominado universitario, valorando su impacto en la promoción y desarrollo de la investigación científica y en la producción de conocimiento en el ámbito universitario nacional.

\section{Petróleo, educación y democracia en Venezuela contemporánea}

La educación ha sido uno de los principales escenarios de batalla en la confrontación política e ideológica de la Venezuela contemporánea. La construcción del Estado Moderno y Democrático que sigue a la muerte de Juan Vicente Gómez en diciembre de 1935, tuvo mucho que ver con las concepciones educativas que dominaron el debate ideológico que se desarrolló en la década de los años 40 del siglo XX, debate que se centró entre los modelos de una educación de élites, defendida por Arturo Uslar Pietri y representada en la Ley de Educación de $1940^{6}$ y una educación de masas, expresada en la Ley de Educación de 1948, liderada por Luis Beltrán Prieto Figueroa. ${ }^{7}$ No hay que olvidar que ambos fueron Ministros de Educación cuando se aprobaron ambas leyes.

Ahora bien, como Política de Estado, en Venezuela la educación tiene que vincularse necesariamente con el tema petrolero y el dilema que se le presentó al liderazgo político que, tras la muerte de Juan Vicente Gómez en diciembre de 1935, condujo el país hacia la democracia. Ese dilema se puede sintetizar en la escogencia entre el destino consuntivo o reproductivo que se le debía dar a la renta petrolera que desde 1930 había venido alimentando las arcas del Estado venezolano. Fue Arturo Uslar Pietri quien, en el editorial del diario Ahora,publicado el 14 de febrero de 1936, llamó la atención del país sobre de la necesidad de transformar la regalía obtenida por la venta de petróleo en el exterior, entendida como un "capital natural"en riqueza productiva con su lema "Sembrar el petróleo". ${ }^{8}$

Como propietario del subsuelo donde se encuentran los yacimientos petrolíferos, es el Estado venezolano el primer beneficiario de aquella riqueza y, frente a ello, cabían dos opciones: Gastarlo socialmente en obras y servicios o reproducirlo transformándolo en capital privado. En esta disyuntiva, para Acción Democrática se trata de construir un Capitalismo de Estado, mientras que para

\footnotetext{
6 Arturo Uslar Pietri. Educar para Venezuela. (Madrid: Editorial Lisbona 1982), 238 y ss.

7 Luis Beltrán Prieto Figueroa. De una educación de castas a una educación de masas. (Caracas: Fondo Editorial IPASME. 2008). 221 y ss.

8 Arturo Uslar Pietri. De una a otra Venezuela. (Caracas: Monte Ávila editores. 1972), 73.
} 
Uslar Pietri debieran ser los empresarios "los creadores del capitalismo venezolano", mientras el Estado participa en esa riqueza, "por medios puramente impositivos."

Rómulo Betancourt, líder de Acción Democrática y Presidente de la Junta Revolucionaria de Gobierno que el 18 de octubre de 1945 derrocó al gobierno del General Isaías Medina Angarita, en la obra Venezuela política y petróleo dedica uno de sus capítulos a la siembra del petróleo, pero desde una perspectiva eminentemente estatista. En su Mensaje del $1^{\circ}$ de enero de 1948, Betancourt expone lo siguiente: "Nuestra actual prosperidad obedece básicamente, al auge del petróleo en la posguerra. La siembra del petróleo, mediante el impulso del crédito cuantioso a las industrias reproductivas, apenas comienza a dar sus frutos. Dispone de poderosos recursos financieros el Estado y circula dinero en abundancia, porque el petróleo se está vendiendo en los mercados del exterior a precios excepcionales, y porque el Gobierno actual ha recabado una participación creciente en el producido de una riqueza de la cual somos los legítimos dueños." 10

Frente a una población "agobiada por la generalizada pobreza y la dificultad para alimentarse, vestirse, curarse, educarse" el gobierno cívico-militar, surgido de la "Revolución de octubre" de 1945, optó por una política de acción inmediata basada en el propósito de "alcanzar el pleno empleo; el de elevar los ingresos de los empleados, obreros y campesinos, y el de abastecer el país de mercancías esenciales, procurando por diversos arbitrios controlar el costo de la vida."11

A la par del aumento del gasto público en empleo, salud y educación y de dinero para las importaciones de bienes de consumo masivo, el gobierno crea en 1946 la Corporación Venezolana de Fomento (CBF)“dotada de recursos económicos cuantiosos, que para fines de 1948 se acercaba a los 400 millones de bolívares". Este organismo se crea como instrumento del Estado "para impulsar y planificar la producción."'Tal propósito se justifica porque: "El Estado, rico en recursos fiscales, debía acelerar el tránsito de la producción no petrolera, lastrada de rezagos feudales, hacia otra de moderna fisonomía industrial. Pero controlando, orientando y condicionando ese proceso, para que no se produjera anárquicamente y para que no culminara en la creación de una prepotente oligarquía de los negocios, desconectada de las necesidades del país y reacia a compartir beneficios con trabajadores y consumidores. ${ }^{\prime 12}$

Mientras que para Uslar Pietri, la renta petrolera - en su destino deseado "debería más bien convertirse en capital privado para dar cauce y cabida a la libre iniciativa individual y a una auténtica democracia", ${ }^{13}$ según la observación que hacen de su pensamiento Asdrúbal Baptista y Bernard Mommer; para Betancourt, Pérez Alfonso y el liderazgo de $\mathrm{AD}$, la etapa consuntiva, entendida como distribución por parte del Estado del ingreso petrolero a través del gasto público, era una etapa previa y necesaria a la inversión reproductiva dirigida por el Estado

9 Tomado de: Asdrúbal Baptista y Bernard Mommer. El petróleo el en pensamiento económico venezolano. (Caracas: Ediciones IESA. 1999), 24.

10 Rómulo Betancourt. Venezuela política y petróleo. (Bogotá: Editorial Senderos. 1969), 350.

11 Ibíd, 352.

12 Ibid, 378.

13 Asdrúbal Baptista y Bernard Mommer. Op. Cit, 29. 
Empresario. Sin embargo, esta "absorción consuntiva de la renta (...) muy pronto se vio desbordada por la cuantía del ingreso petrolero" ${ }^{14}$ y de etapa coyuntural se transformó en modelo estructural generando la dependencia permanente -hasta el presente- del país a los vaivenes del ingreso petrolero.

Como bien señala Harrison Sabin Howard en su estudio sobre este periodo: "El enorme aumento de los ingresos gubernamentales, que llegaron en 1948 a 1.308.577.829 bolívares, es decir, el doble de todo el ingreso percibido por el gobierno durante los últimos años de Medina, creó el sentimiento (a pesar de que se conocía abiertamente que no era así) de un avance importante hacía la soberanía económica."15

Esta nueva situación financiera del país es la que Uslar Pietri denomina el Festín de Baltasar, donde las importaciones suben y la producción nacional decae. En síntesis, una nación fingida, disfrazada de rica, gracias a la riqueza transitoria generada por el petróleo. En este contexto, las estadísticas de la expansión de los servicios educativos que presenta Betancourt para esos tres años de gobierno son fantásticas: el presupuesto del Ministerio de Educación pasó de 38 millones de bolívares en 1945 a 119 millones en 1948. Sumando las inversiones públicas, dice Betancourt que el presupuesto real de educación sobrepasó los 250 millones de bolívares equivalentes en ese momento a más de 80 millones de dólares. ${ }^{16} \mathrm{Es}$ sobre esta base material tomada de la renta petrolera que se establece en el país la Educación de Masas. Para Prieto Figueroa, ideólogo y defensor de la Educación de Masas: "cuando hablamos de un humanismo democrático al mismo tiempo que de una educación de masas, estamos conjugando dos términos que expresan el propósito de formar hombres en nuestro país que tengan los pies en el suelo y que se dediquen en forma entusiasta y fervorosa al cultivo de la democracia, lo que implica la formación de hábitos y aptitudes para vivir en una nación democrática." 17

Se trata, en consecuencia, de una relación estrecha entre Educación y Democracia, ya que esta involucra la participación de las masas y exige, por tanto, la construcción de un sistema educativo sobre el cual se pueda soportar el modelo de la democracia representativa. Cuando revisamos su obra De una educación de castas a una educación de masas y nos detenemos a analizar los indicadores que permiten hablar del éxito de esa transición o de esa "Revolución Educativa", apreciamos que lo fundamental está en la expansión de la matrícula escolar y en la cantidad de obras de infraestructura escolar que se construyen, contando, además, con los servicios de alimentación y salud que garantizan el éxito dela política educativa. Este es un modelo que privilegia la cantidad sobre la calidad. El éxito de la política educativa se mide en alumnos atendidos y escuelas construidas.

En la Ley de 1940, la educación es asumida como un proceso integrador del individuo al cual se le debe "adiestrar(...) para el desarrollo de su capacidad productora, intelectual y técnica y fortalecer los sentimientos de cooperación y solidaridad

$14 \quad$ Ibíd. p. 68.

15 Harrison Sabin Howard. Rómulo Gallegos y la Revolución Burguesa en Venezuela. (Caracas: Monte Ávila editores. 1976), 228.

16 Rómulo Betancourt. Op. Cit. 1969, 491.

17 Luis Beltrán Prieto Figueroa. El humanismo democrático y la educación. (Caracas: Editorial Las Novedades. 1959), 55. 
nacional". ${ }^{18}$ Es una visión más económica que política. Podríamos decir, en este sentido, que la educación es la herramienta para "sembrar el petróleo", capacita a los trabajadores para que junto al empresariado transformen la Venezuela rentística en una nación productiva.

Mientras que para Uslar Pietri, el ingreso petrolero es "riqueza transitoria y socialmente no ganada" que debe transformarse mediante el desarrollo agrícola e industrial del país en capital privado y riqueza producida por los factores del trabajo ${ }^{19}$; para Betancourt es el Estado el que debe transformarse en el "estimulador, financiador y orientador de las actividades económicas que tienen a hacer más abundante y variada la producción doméstica; y como Estado empresario, para desarrollar algunas actividades directamente vinculadas al interés público (la siderúrgica, electrificación, comunicaciones radiotelegráficas y telefónicas, transporte)"20

Este proceso político se interrumpe con el golpe militar de 1948, en este caso, contra el gobierno de Rómulo Gallegos. Al instaurarse el nuevo régimen militar, la Ley de Educación de 1948 es sustituida por el Estatuto Provisional de Educación de 25 de mayo de 1949. En 1955 se aprueba una nueva Ley de Educación. El Estatuto de 1949 tuvo como novedad restituir la enseñanza religiosa que ya había sido incorporada en la Ley de 1940. Por eso, como bien señala Alexis Márquez Rodríguez: "La ley de 1955 no agrega nada de particular interés a la copiosa legislación educacional que hemos tenido. Sus normas se alinean, más o menos, dentro de lo que venía siendo habitual desde 1940, con la sola y fugaz interrupción representada por las innovaciones de 1948."21

Esta alineación legislativa es la que permite explicar cómo al instaurarse la democracia en 1958, el nuevo régimen político dirigido por Acción Democrática y el partido socialcristiano, COPEI, pudo impulsar sus políticas de masificación educativa sin cambiar de Ley de Educación de 1955. Será en 1980 que surja una nueva Ley Orgánica de Educación, pero en los marcos ideológicos y doctrinarios de la Ley de 1948 ya que está fundada en el principio del Estado Docente que, como se señala en su Artículo 4º la educación se entiende como un "servicio público prestado por el Estado, o impartido por los particulares dentro de los principios y normas establecidos en la ley, bajo la suprema inspección y vigilancia de aquel y con su estímulo y protección moral y material." Ahora bien, ¿cómo evolucionó este proceso educativo y por qué entra en crisis en la década de los años $90 ?$

\section{De la política de masificación educativa de los 60 a la crisis del sistema es- colar en la década de los 80}

Al revisar las cifras del comportamiento de la matrícula escolar venezolana entre 1958 y 1990, podemos apreciar que, en términos cuantitativos, la política

18 Arturo Uslar Pietri. Op. Cit. 1982, 254.

19 Tomado de: Fabio Maldonado Veloza. El proceso petrolero. Sus paradigmas kuhnianos. (Mérida: Consejo de Publicaciones de la ULA. 1996), 143.

20 Rómulo Betancourt. Op. Cit. 1969, 380.

21 Alexis Márquez Rodríguez. Doctrina y proceso de la educación en Venezuela. (Caracas: 1964), 146. 
de masificación impulsada por el Estado, desde sus antecedentes en 1947 y a partir de 1958, fue un éxito. Para una población de 6.942.137 habitantes, en 1958 se matriculan 817.488 alumnos para darnos una tasa bruta de escolaridad del 11,8 \%. Cuando Raúl Leoni le entrega la presidencia de la República a Rafael Caldera en marzo de 1969, la población del país se contaba en 10.247.303 habitantes y la matrícula escolar en 2.216 .398 alumnos, para una tasa bruta de escolaridad del orden de $21,6 \%$.

En 1980, cuando se decreta la Ley Orgánica de Educación, para una población total de 15.023.879 habitantes, la tasa de escolaridad había llegado al 28,6 \%, reflejando una población escolarizada de 4.302 .972 personas. A pesar de la crisis económica que se desata en 1983, la tasa bruta de escolaridad se remonta entre 1986 y 1987 al 32,2 \%, la más alta en todo el período. ${ }^{22}$ Estas cifras, indiscutiblemente, expresan una realidad. Sin embargo, el sistema en su conjunto vive un proceso de desajuste que lo lleva progresivamente a la crisis. ¿Qué ha pasado?, que los gobiernos de la democracia representativa, tanto de AD como de COPEI le dieron prioridad a la expansión y crecimiento cuantitativo del sistema educativo, en sus niveles de educación primaria y secundaria, sacrificando la calidad.

Luis Bravo Jáuregui, en su estudio sobre La Escuela Venezolanaseñala que a pesar de que el discurso oficial estuvo apegado a la idea de propiciar desde 1958 una educación de calidad, lo que ha sucedido en la práctica es que el énfasis se ha puesto fundamentalmente en la expansión de la cobertura, "impulsada por una inercia institucional que hacía de la expansión del servicio educativo su leit motiv."Y esta realidad es la que empiezan a detectar los informes técnicos y los estudios que a partir de la década de los años 80 se desarrollan en el país.

En 1986, la Comisión Presidencial para el Estudio del Proyecto Nacional, coordinada por el Dr. Arturo Uslar Pietri y en la que participan, entre otros, el Dr. Luis Beltrán Prieto Figueroa, presenta una primera aproximación al tema y en él se destacan las siguientes fallas y deficiencias en relación con el funcionamiento de los principios del Estado docente:

1. Se trata de un sistema educativo excesivamente escolar en todos sus niveles y modalidades, en el que se ha confundido el concepto de educación en sentido lato, con el de educación sistemática y formal, correspondiente a la escolarización. A este respecto señala: "La idea predominante en los contenidos curriculares de todos los niveles es que al individuo debe enseñársele todo en el medio escolar, lo cual niega la importancia educativa de los diferentes medios donde se mueve el individuo. ${ }^{\prime 23}$ Esta distinción será de fundamental importancia en el debate constituyente de 1999 entre el Estado-docente y la Sociedad Educadora.

2. Perversión del principio igualitario. En ese sentido, para la Comisión: "Los tres supuestos básicos, sustento de estos fines son: que todos los planteles son iguales y tienen la posibilidad y medios para impartir un mismo y solo tipo de enseñanza;

22 Luis Bravo Jáuregui. La escuela venezolana. Educación de masas, políticas y resultados a partir de 1958. (Caracas: Ediciones Episteme. 1999), 80.

23 Arturo Uslar Pietri. (Coord.) Comisión Presidencial para el Estudio del Proyecto Nacional. (Caracas: Presidencia de la República. 1986), 15. 
que todos los docentes tienen la misma preparación y capacidad para impartir un enseñanza que exige del maestro elevadas capacidades de inteligencia, creatividad y discernimiento; y por último, que todos los educandos tienen las mismas características para participar en un sistema único que no toma en cuenta las diferencias personales. ${ }^{\prime 24}$ (Subrayado nuestro). En ese sentido, se trata de un sistema excesivamente uniforme que desconoce "la pluralidad local, regional, cultural y étnica..." del país.

3. La masificación como problema. Sin negar los alcances políticos y sociales de la expansión del servicio público, la Comisión señala como efectos negativos de la masificación los siguientes: "...la incorporación de docentes no siempre bien calificados,(...) el congestionamiento y hacinamiento en aulas, la marginalidad dentro del proceso escolar y la carencia de una infraestructura mínima necesaria." 25

Todos estos problemas, lejos de superarse en la década de los 90, se agravaron. En los documentos que elabora la Comisión Presidencial para la Reforma del Estado (COPRE), el denominado Un Proyecto Educativo para la modernización y la democracia, viene a ser uno de los más completos no solo por las apreciaciones críticas que hace acerca del funcionamiento del sistema escolar, sino también por su fundamentación estadística actualizada con estudios propios de campo.

Entendiendo la educación como un "sistema de distribución del capital cultu$\mathrm{ral}^{\prime 26}$ la COPRE destaca cómo una serie de desequilibrios acumulados tienden a neutralizar los logros alcanzados, generando "disfuncionalidades entre el sistema educativo y el conjunto de la sociedad", nudos críticos que enumera de la siguiente manera:

1. Persistencia de niveles muy bajos de ingresos en amplios sectores de la población, que traen consigo dificultades y limitaciones para la incorporación al medio escolar.

2. Fisura entre la formación de la fuerza de trabajo y las necesidades de la estrategia económica ya que la diversificación de la educación media y superior no han producido los resultados esperados.

3. Baja correspondencia entre las permanentes exigencias del cambio científico-tecnológico y los contenidos de la educación formal.

4. Ausencia de un mensaje educativo coherente, canalizado a través de los diferentes agentes que ejercen influencia transformadora en la población. ${ }^{27}$

Y en efecto, a estos factores generales se suma el aumento del índice de ausentismo, repitencia, y retardo escolar, especialmente en los sectores de menores recursos. Estos problemas, prácticamente, anulan el esfuerzo gubernamental y social por desarrollar el sistema educativo nacional de masas. En 1999, cuando el país vive un conflictivo proceso constituyente, en el documento deno-

24 Ibid, 17.

25 Ibid, 21

26 Comisión Presidencial para la Reforma del Estado (COPRE). Un proyecto educativo para la modernización y la democratización. (Caracas: Ediciones de la COPRE. 1990), 19.

27 Ibid, 19 y 20. 
minado Aportes para el debate sobre la Constituyente Educativa,el propio Ministerio de Educación señala las cifras que evidencian la regresión que vive el sistema escolar público en la década de los noventa.

1. Déficit de aulas y maestros, estimados estos últimos para el año 2000 en 130.000 nuevos educadores.

2. Dos millones de niños y jóvenes que no trabajan ni estudian.

3. Déficit presupuestario que se expresa en la reducción del gasto educativo a un 3\% en la década de los noventa y del cual el $45 \%$ no va dirigido a actividades directamente educativas.

4. Cifras de analfabetismo creciente, llegando a contarse en un $10,6 \%$ el analfabetismo absoluto de la fuerza laboral.

5. Burocratización excesiva de la estructura central del Ministerio de Educación, que absorbe una parte sustancial del presupuesto educativo del país, a la cual se suma la "cultura clientelar, demagógica y corrupta predominante en buena parte del sistema educativo".

6. Métodos, procedimientos y modelos educativos, pedagógicos y didácticos atrasados.

7. Separación de la escuela de su entorno social.

8. Creciente tendencia a la privatización de la educación en todos sus niveles. Las cifras que se aportan son elocuentes: $25 \%$ de la matrícula en preescolar, $23 \%$ en básica, $40 \%$ en media y $40 \%$ en superior. ${ }^{28}$

Es en este contexto de crisis y de búsqueda de un nuevo proyecto educativo nacional que se desenvuelve el proceso constituyente venezolano liderado desde la Presidencia de la República por Hugo Chávez Frías, luego de asumir las riendas del país en las elecciones de diciembre de 1998.

\section{La educación en el periodo de la "Revolución Bolivariana" y del "Socialis- mo del siglo XXI". (2000-2016)}

Lo primero que hay que señalar es que el gobierno lideradodesde el 2000 hasta el año 2013, por el extinto presidente Chávez, debe dividirse en periodos relacionados con el proyecto político-ideológico que se va imponiendo desde las estructuras del gobierno, ya que estos cambios van a tener efectos en la organización del Estado, el funcionamiento de los poderes públicos $\mathbf{y}$, por ende, en las políticas que el gobierno va implantando en un itinerario que va del nacionalismo inicial, bolivariano y antimperialista, fundado en el "Árbol de las tres raíces" 29 , al "Socialismo del siglo XXI" 30 aunque alineado en la práctica con el socialismo cubano. ${ }^{31}$

28 Ministerio de Educación. Aportes para el debate sobre la Constituyente Educativa. (Caracas: Publicación de la Dirección General Sectorial de Planificación y Presupuesto: Proyecto Constituyente Educativa. 1999), 11-13.

29 Alberto Garrido. Documentos de la Revolución Bolivariana. (Mérida: Producciones Karol C. A. 2004), 101 y ss.

30 Heinz Dieterich. Hugo Chávez y el Socialismo del siglo XXI. (Barquisimeto: Edición del Gobierno Revolucionario del estado portuguesa. 2005), 175 y ss.

31 Sobre esta evolución puede consultarse: Hugo Chávez. El discurso de la Unidad. (Caracas: Ediciones "Socialismo del siglo XXI". No 1 , enero de 2007). 
En este sentido, creemos conveniente para el análisis diferenciar los siguientes periodos o fases de la denominada "Revolución Bolivariana":

1. 1998: Triunfo electoral de Hugo Chávez a partir de una amplia alianza de partidos, organizaciones e individualidades bajo las banderas de la Constituyente.

2. 1999: Convocatoria y realización de la Asamblea Nacional Constituyente que elabora la Constitución aprobada por referendo el 15 de diciembre de ese mismo año.

3. 2000: Relegitimación de los poderes públicos en elecciones generales realizadas el 30 de julio 2000, en el marco jurídico de la nueva Constitución. ${ }^{32}$

4. 2001-2007: El Presidente es reelecto e inicia su segundo mandato de gobierno elaborando por medio de una Ley Habilitante, figura que delega la facultad de legislar al Presidente y la cual aparece por primera vez en la Constitución de 1999. La primera Ley Habilitante fue solicitada en el año 1999 y otorgada por un lapso de seis meses, mediante esta se aprobaron 53 decretos-ley entre el 2000 y el 2001, lo cual llevó a una primera fisura en el bloque político aliado al Presidente Chávez con la salida de Luis Miquelena y un grupo de dirigentes fundadores del partido V República.

5. 2007-2013: Gracias al marco jurídico que le proporciona una tercera Ley Habilitante solicitada en el 2007 y otorgada para un período de 18 meses, el Presidente Chávez aprueba el Proyecto Nacional Simón Bolívar, Primer Plan Socialista del Desarrollo Económico y Social para el periodo 2007-2013. En ese mismo año, que no dudamos en calificar de giro estratégico del modelo constitucional de 1999 a un proyecto político socialista de inspiración soviética, ${ }^{33}$ el Presidente propone una reforma constitucional para transformar a Venezuela en un Estado Socialista. La reformapropuesta es llevada a Referendo Consultivo pero no es aprobada electoralmente. Sin embargo, la reforma se impone por vía ejecutiva creándose un Poder Comunal paralelo a lo establecido en la Constitución de 1999.

6. 2013-2016: Muere en marzo de 2013 el Presidente Chávez y su sucesor Nicolás Maduro asume el poder mediante unas reñidas elecciones -acusadas de fraudulentas por la oposición- celebradas el 14 de abril de ese año, recibiendo un país en un acelerado proceso de crisis económica que se agravacon la caída de los precios del petróleo a partir del 2014. No hay cambio de políticas, sino continuación de las que habían sido legadas en los dos periodos de gobierno del Presidente Chávez.

32 En este proceso electoral, además de la elección presidencial se realizaron elecciones para gobernadores, asambleas legislativas, alcaldes, concejos municipales y diputados para el nuevo parlamento, ahora denominado Asamblea Nacional.

33 Aquí nos referimos a evidencias como el unipartidismo revolucionario, la estatización de la economía a todos sus niveles y el estado comunal como reminiscencia de los soviets. Temas que asomamos para abordar el análisis científico del modelo socialista que se quiere implantar en el país y para impulsar su comprensión histórica. El caudillismo sería su particularidad latinoamericana y el populismo rentista petrolero, su singularidad venezolana. 
Es, en este marco jurídico-político e ideológico de cambios, que se debe analizar la educación y las políticas educativas implementadas desde el Estado venezolano. ¿Cuáles son las principales reformas y sus referentes legislativos?

En primer lugar, el marco doctrinario lo establece la Constitución de la República Bolivariana de Venezuela, la cual en su Artículo 102señala lo siguiente:

"La educación es un derecho humano y un deber social fundamental, es democrática, gratuita y obligatoria. El Estado la asumirá como función indeclinable y de máximo interés en todos sus niveles y modalidades... (...) La educación es un servicio público y está fundamentada en el respeto a todas las corrientes del pensamiento... (...) El Estado, con la participación de las familias y la sociedad, promoverá el proceso de educación ciudadana de acuerdo a los principios contenidos en esta Constitución y en la ley." 34

En este mismo texto constitucional la obligatoriedad queda establecida desde el maternal hasta el nivel medio y diversificado, y la gratuidad hasta el pregrado universitario (Artículo 103). Para tales efectos, el Estado deberá asumir el gasto educativo como una inversión prioritaria "de conformidad con las recomendaciones de la Organización de las Naciones Unidas." Se amplía la cobertura de la gratuidad "a las personas con necesidades especiales o con discapacidad y a quienes se encuentren privados de su libertad o carezcan de condiciones básicas para su incorporación y permanencia en el sistema educativo." Con el texto aprobado y publicado en la Gaceta Oficial de la República en 1999, el Estado Docente se afirma como doctrina oficial de la nueva República bolivariana. Ahora bien, ¿cuál es el marco legal que empieza a construirse para hacer efectivo el mandato constitucional?

En un primer momento, entre el 2000 y el 2006, la transformación educativa que busca llevar adelante el gobierno bolivariano se traduce en la creación del denominado Sistema Educativo Bolivariano (SEB), el cual se plantea como objetivo prioritario ampliar velozmente la cobertura escolar. Para ello, se crean los siguientes programas y proyectos bandera: "Simoncito", para el nivel preescolar ahoradenominado maternal; Escuela Bolivariana, para la educación primaria; el "Liceo Bolivariano" y las "Técnicas Robinsonianas", para el nivel secundario y en 2003 las "Misiones Educativas", inicialmente para combatir el analfabetismo y reactivar la educación de adultos. Todos se asumen como medios para ampliar la inclusión, en particular de los grupos que históricamente habían quedado excluidos de los beneficios educativos. Sin embargo, la política de las Misiones Sociales no se asume como emergente y transitoria, sino como una respuestaa la incapacidad que tienen las instituciones del Estado venezolano para dar respuesta a aquellas demandas, ${ }^{35}$ constituyéndose en una institucionalidad paralela dirigida desde la propia Presidencia de la República. Este tema, que requeriría un estudio aparte, es de fundamental importancia para poder evaluar el impac-

34 Constitución de la República Bolivariana de Venezuela. En: http://www.minci.gob.ve/wp-content/uploads/2011/04/CONSTITUCION.pdf (02-04-2017)

35 Luis Bonilla-Molina y Haiman El Troudi. Historia de la Revolución Bolivariana. Pequeña Crónica 1948-2004. (Caracas: Ministerio de Comunicación e Información. 2004), 228. 
to que en la organización y funcionamiento del Estado venezolano ha tenido la estrategia de las Misiones como dimensión social del Proyecto Político Bolivariano.

Como bien señala Tito Lacruz en el estudio que realiza sobre este particular, el universo de las misiones es variado: algunas tienen un nivel de estructuración muy alto, como "Barrio Adentro" en el sector salud; otras son operativas como la "Misión Identidad" y otras no son sino la formalización de una política pública sectorial como la "Misión Vivienda". En el área económica, la "Misión Vuelvan Caras" busca promover un nuevo modelo productivo alternativo y comunitario en el campo y la "Misión Mercal" 36 competir con la red privada de comercio privado minorista, distribuyendo alimentos subsidiados, mientras hay misiones como "Piar" y "Miranda" que son prácticamente desconocidas. En el área educativa hay políticas de reforma al interior del Sistema Escolar que se combinan con una estrategia de misiones educativas a todos los niveles que se inician en 2003: "Misión Robinson" I y II en alfabetización de adultos; “Misión Ribas" para culminar la educación secundaria; y la "Misión Sucre", inicialmente como política de inclusión de población rezagada y excluida de la Educación Superior. ${ }^{37}$

A partir del año 2007, se acelera la aprobación de la propuesta del Currículo Nacional Bolivariano (CNB) y en 2009 se aprueba un controvertida Ley Orgánica de Educación (LOE). En líneas generales, el balance del primer decenio del proceso de transformación del sistema educativo venezolano, iniciado con la Constituyente Educativa de 1999, lo podemos resumir en los siguientes hitos:

- Implementación de la Escuela Bolivariana

- La ratificación de la gratuidad de la enseñanza y la eliminación de la matrícula escolar

- La revisión y aprobación del Currículo Bolivariano

- La aprobación el 13 de agosto de 2009de la Ley Orgánica de Educación.

- El establecimiento desde 2003 de las Misiones Educativas: Robinson, Ribas, Sucre y Vuelvan Caras.

- El Plan de Alfabetización

- La expansión del Programa de Alimentación Escolar

- La oficialización del Currículo de Educación Inicial y Sistematización del ProyectoSimoncito.

- El acceso a las nuevas tecnologías de información y comunicación a través de los Centros Bolivarianos de Informática y Telemática (CBIT)

- El impulso moderado a la construcción y rehabilitación de la planta física escolar (objetivo en mora)

- El desarrollo de proyectos productivos en las escuelas técnicas y zamoranas.

36 Las siglas se refieren, primero, a la Empresa Mercado de Alimentos (MERCAL) creada en 2003 para la comercialización y mercadeo de alimentos de primera necesidad, que luego se transformó en Comisión Presidencial para el Abastecimiento Alimentario Misión MERCAL dirigida a garantizar la seguridad alimentaria de la población.

37 Tito Lacruz. "La propuesta social del Gobierno Bolivariano. Las Misiones." En: Pedro Trigo S. J. y otros. Una mirada sobre Venezuela. (Caracas: Fundación Centro Gumilla, 2008), 245-258. 
- El Avance en los proyectos educativos integrales-comunitarios (PEIC) en todo el país.

Este proceso educativo podríamos ubicarlo históricamente en una reedición del paradigma de la educación de masas, aunque busca un cambio de calidad cuando el nuevo gobierno se propone pasar de una "sociedad democrática, participativa y protagónica, multiétnica, pluricultural..." según se establece en el Preámbulo de la Constitución de 1999, a una sociedad que "cimenta sus raíces en fusión de los valores y principios más avanzados de las corrientes humanistas del socialismo y de la herencia histórica del pensamiento de Simón Bolívar", según se señala como directriz en el Proyecto Nacional Simón Bolívar Primer Plan Socialista2007-2013). ${ }^{38}$ ¿De las políticas educativas planteadas cuáles fueron sus ejecutorias?, ¿Qué dicen las estadísticas?

Sobre la política de alfabetización, el país recibe en 2005 el reconocimiento por parte de la UNESCO como "territorio libre de analfabetismo", en el marco de los seis objetivos de la EDUCACIÓN PARA TODOS(2000-2015) propuestos por este organismo internacional en el Foro Mundial sobre la Educación, celebrado en el año 2000 en Dakar, Senegal; en los siguientes ámbitos de acción: 1) lucha contra elVIH-SIDA, 2) primera infancia, 3) salud en la escuela, 4) educación de las niñas y las mujeres, 5) alfabetización de adultos y 6) educación en situaciones de crisis. ${ }^{39}$

Sobre este particular, nuevamente entra en escena el petróleo, ya que el proyecto educativo que se propone llevar a cabo el gobierno liderado por Chávez se va a sustentar en un nuevo ciclo de bonanza petrolera, iniciado en 2004 hasta la caída de los precios en 2014. Como se sabe, el precio del petróleo rondaba los 25dólares en 2003. En 2007 el precio está alrededor de los 64,74 \$, llegando al máximo en 2012 con un precio de 103,42, para la Cesta Venezuela. A partir de julio de 2014 empieza la caída del precio de 99 \$ para llegar a los 44 \$ en enero de 2015 y a los 31 \$ en enero de 2016. ${ }^{40}$ Para un país que ha vivido de la renta petrolera, este comportamiento de la variable petrolero prácticamente determina las políticas educativas que lleva adelante el gobierno bolivariano. Revisemos la evolución de la matricula como indicador de cobertura educativa entre 1999 y 2010.

38 http://www.curricular.info.ve/PNF/pnsb.pdf (02-04-2017)

39 http://unesdoc.unesco.org/images/0012/001211/121147s.pdf (02-04-2017)

40 www.innovaven.org/bda/indnac/ec04pe01.xls(02-04-2017) 
Población incluida en el Sistema Educativo Venezolano 1999-2010

(Dinámica más básica de población y matricula en algún tipo de servicio educativo, oficial y privado)

\begin{tabular}{|c|c|c|c|c|c|}
\hline Años & $\begin{array}{c}\text { Matrícula } \\
\text { Total }\end{array}$ & $\begin{array}{c}\text { Variación } \\
\text { \% }\end{array}$ & $\begin{array}{c}\text { Población } \\
\text { total }\end{array}$ & $\begin{array}{c}\text { Variación } \\
\text { \% }\end{array}$ & $\begin{array}{c}\text { \% matrícula res- } \\
\text { pecto a población }\end{array}$ \\
\hline 1999 & 7.029 .477 & 0,3 & 23.706 .711 & 2,0 & \\
\hline 2000 & 7.303 .155 & 3,9 & 24.169 .744 & 2,0 & 30,2 \\
\hline 2001 & 7.814 .371 & 7,0 & 24.631 .900 & 1,9 & 31,7 \\
\hline 2002 & 8.253 .735 & 5,6 & 25.093 .337 & 1,9 & 32,9 \\
\hline $2003^{*}$ & 10.651 .645 & 29,1 & 25.553 .504 & 1,8 & 41,7 \\
\hline 2004 & 12.950 .267 & 21,6 & 26.127 .351 & 2,2 & 49,6 \\
\hline 2005 & 13.690 .841 & 5,7 & 26.577 .423 & 1,7 & 51,5 \\
\hline 2006 & 13.954 .105 & 1,9 & 27.030 .136 & 1,7 & 51,6 \\
\hline 2007 & 11.281 .506 & $-19,2$ & 27.483 .208 & 1,7 & 41,0 \\
\hline 2008 & 11.209 .325 & $-0,6$ & 27.934 .783 & 1,6 & 40,1 \\
\hline 2009 & 10.639 .590 & $-5,1$ & 28.384 .132 & 1,6 & 37,5 \\
\hline 2010 & & & 28.833 .845 & & \\
\hline
\end{tabular}

*NOTA: A partir de este año (2003) la matrícula total del sistema incluye misiones FUENTE autorizada:Bravo Jáuregui, Luis. 12 años de educación en Venezuela (Escolaridad y alfabetización 1999-2010). P. $6 .{ }^{41}$

De este cuadro lo más significativo es el salto que se da a partir de 2003 cuando entran en escena las Misiones Educativas, sector al que se le debe este aumento de escolaridad, pero con un dato que se podrá apreciar mejor a partir de 2013. Se trata de una política que se desarrolla paralelamente al sistema escolar oficial y que, a la larga, al cumplir sus objetivos, tendrá efectos en la caída nuevamente de la matrícula escolar. Veamos el comportamiento del sistema diferenciando el sector oficial de los planteles privados y excluyendo la matrícula universitaria.

Dinámica matricular más básica inscritos en el Sistema Escolar y Misiones (A partir de 2003)

(Excluye Educación Universitaria, antes de 2009, Educación Superior) Educación oficial y privada

\begin{tabular}{|l|l|l|l|}
\hline Años escolares & Total & Oficial & Privado \\
\hline $2000-2001$ & 6.961 .421 & 5.685 .389 & 1.276 .032 \\
\hline $2001-2002$ & 7.372 .234 & 6.053 .962 & 1.318 .282 \\
\hline $2002-2003$ & 9.533 .726 & 8.249 .408 & 1.284 .318 \\
\hline $2003-2004$ & 11.342 .750 & 10.056 .186 & 1.286 .564 \\
\hline $2004-2005$ & 11.780 .889 & 10.439 .487 & 1.341 .402 \\
\hline
\end{tabular}




\begin{tabular}{|l|l|l|l|}
\hline Años escolares & Total & Oficial & Privado \\
\hline $2005-2006$ & 11.618 .747 & 11.618 .747 & 1.402 .560 \\
\hline $2006-2007$ & 9.183 .812 & 7.679 .290 & 1.504 .523 \\
\hline $2007-2008$ & 9.443 .067 & 7.887 .399 & 1.555 .668 \\
\hline $2008-2009$ & 8.530 .259 & 6.899 .197 & 1.631 .062 \\
\hline $2009-2010$ & 8.493 .529 & 6.836 .224 & 1.657 .305 \\
\hline
\end{tabular}

Fuente: Bravo Jáuregui, Luis. 12 años de educación en Venezuela (Escolaridad y alfabetización 1999-2010). P. $6 .{ }^{42}$

Entre el 2000 y 2005 casi se duplicó la matrícula universitaria, siendo la única experiencia de los países de América Latina; en este sentido, el balance sobre las Universidades de América Latina y el Caribe, siguiendo el análisis de Diana Soto Arango y Aracelis Forero nos lo presenta así: "las universidades del Caribe y Latinoamericanas ingresan a este milenio con características propias y diferentes a las norteamericanas y europeas. De esta manera, se puede diferenciar, primero que la cobertura educativa es mayor en los países norteamericanos y europeos. En estas se duplicó la población estudiantil en una sola década, mientras que en los países latinoamericanos ha aumentado pero no con tal notoriedad. Segundo, el financiamiento de la universidad por parte del Estado, se sometió a nuevos tipos de indicadores como el rendimiento, que han dado como resultado la desigualdad entre estas instituciones; las universidades públicas se han visto abocadas a generar nuevas estrategias para la financiación de sus instituciones como ampliar la oferta educativa, el incremento de las matrículas y la ampliación de los cupos. Tercero, se ha introducido la condición de calidad de la Educación, como un compromiso que asumen las universidades y que continuamente buscan dar respuestas a los nuevos desafíos de los avances científicos y tecnológicos. Cuarto, desde el proceso generado en Bolonia en 1998, la internacionalización de la universidad se ha asimilado a la movilidad de profesores y estudiantes con homologación de estudios (créditos) y convalidación de títulos que varían en esta movilidad según las crisis económicas de sus países y emigran a otros donde tengan posibilidad de empleo. Quinto, la formación y la investigación de altos niveles académicos y científicos." ${ }^{43}$ Estas variantes nos permiten evaluar a su vez el estado de la universidad venezolana en estos años, 1. Si bien incrementó la matrícula logrando casi duplicarla en el primer lustro del siglo XXI, también es verdad que no cumplió con las exigencias que exigía ese crecimiento, como es el caso, incrementando la calidad; no pudo conciliar la cantidad con la calidad; 2 . El tema de la internacionalización se vio restringido al colocar restricciones a los investigadores para poder visibilizar sus trabajos en los congresos internacionales, situación que se fue incrementando hasta que en año 2008 y 2009 se limitaron casi absolutamente esos derechos. Igualmente, se

42 http://www.venescopio.org.ve/web/wp-content/uploads/Informe-de-escolaridad-en-Vzla-1999-2011.pdf(03-04-2017)

43 Diana Elvira Soto Arango y Aracely Forero Romero, "La Universidad Latinoamericana y del Caribe en los desafíos del Siglo XXI2, Revista Historia de la Educación Latinoamericana. vol. 18 no. 26 (2016): 279ss 
fue reduciendo los apoyos para realizar postgrados, y especialmente, los doctorados en el exterior, lo que trajo como consecuencia la limitación de participar en los principales centros de conocimiento de los países de punta para acortar la brecha tecnológica y científica.

En este cuadro también se aprecia que el éxito de la política educativa ha sido limitar el crecimiento de la educación privada ampliando la cobertura de la educación en planteles oficiales. Sin embargo, se aprecia que ese crecimiento no es continuo. Hay una caída del crecimiento matricular general a partir de 2006 , tendencia que se mantiene por el descenso de la cobertura educativa en los planteles oficiales, mientras la educación privada crece poco, pero crece. En este mismo estudio que venimos citando, del investigador Luis Bravo Jáuregui, se puede apreciar que el impacto de las Misiones Educativas empieza a estancarse a partir de 2006, de tal manera que la matricula oficial se desenvuelve a partir de ese año escolar de la siguiente manera:

Matrícula de los niveles y modalidades del sistema

(Sin Misiones Educativas y sin Educación Superior)

\begin{tabular}{|l|l|l|l|}
\hline Años escolares & Total & Oficial & Privado \\
\hline $2006-2007$ & 7.667 .384 & 6.162 .861 & 1.504 .523 \\
\hline $2007-8$ & 7.598 .497 & 6.042 .829 & 1.555 .668 \\
\hline $2008-9$ & 7.702 .749 & 6.071 .687 & 1.631 .062 \\
\hline $2009-10$ & 7.735 .815 & 6.078 .510 & 1.667 .305 \\
\hline
\end{tabular}

Fuente: Bravo Jáuregui, Luis. 12 años de educación en Venezuela (Escolaridad y alfabetización 1999-2010). P. $6{ }^{44}$

En este sentido, a partir de 2006 se aprecia una contracción y una caída de la matrícula en términos absolutos, ya que cae por debajo de la cifra de alumnos en planteles oficiales en el año escolar 2002-2003, que estaba por encima de los $8 \mathrm{mi}$ llones de alumnos. Veamos por nivel: En el año escolar 1998-9 se contabilizaron 882.468 niños en el nivel preescolar. Para el periodo 2002-3 la cifra de alumnos atendidos es de 946.761, es decir, hay un leve crecimiento. Para el 2005-6 la cifra pasa a 1.355.373 alumnos, sumando 344.427 inscritos en sistemas de atención no convencional. En el año escolar 2009-10 la cifra sube a 1.563.117 de niños atendidos. Es decir que en este nivel hay un crecimiento en la expansión de la matrícula en toda la década. Si pasamos a la educación primaria, entre el 2005 y el 2010, apreciamos lo siguiente:

44 http://www.venescopio.org.ve/web/wp-content/uploads/Informe-de-escolaridad-en-Vzla-1999-2011.pdf (05-04-2017) 
Educación Primaria (Antes Básica 1-6 Grados)

\begin{tabular}{|l|l|l|l|}
\hline Años escolares & $\mathbf{1}^{\mathbf{o}}$ a $\mathbf{6}^{\mathbf{o}}$ grado & Oficial & Privada \\
\hline $2005-6$ & 3.452 .062 & 2.953 .134 & 498.928 \\
\hline $2006-7$ & 3.521 .139 & 2.976 .275 & 544.864 \\
\hline $2007-8$ & 3.439 .199 & 2.887 .757 & 551.442 \\
\hline $2008-9$ & 3.432 .592 & 2.846 .496 & 586.096 \\
\hline $2009-10$ & 3.428 .361 & 2.826 .681 & 599.670 \\
\hline
\end{tabular}

FUENTE: Bravo Jáuregui, Luis. 12 años de educación en Venezuela (Escolaridad y alfabetización 1999-2010). P. $6 .^{45}$

Sobre la Educación Secundaria o Media, estas son las cifras de matrícula de 2004 a 2008:

Educación Media Años Escolares Total Oficial Privada (2004-2008)

$1^{\mathrm{o}}-3^{\mathrm{o}} / 4^{\mathrm{o}}-6^{\mathrm{o}} \mathrm{ANO}$

\begin{tabular}{|l|l|l|l|l|l|}
\hline $\begin{array}{c}\text { Años } \\
\text { escolares }\end{array}$ & \multicolumn{1}{|c|}{ Oficial } & \multicolumn{1}{|c|}{ Privada } & $\mathbf{1}^{\mathbf{o}}$ a 3er año & $\mathbf{4}^{\mathbf{o}} \mathbf{a} \mathbf{6}^{\mathbf{o}}$ & \multicolumn{1}{|c|}{ Total } \\
\hline $2004-5$ & 1.529 .051 & 499.337 & 1.408 .490 & 619.898 & 2.028 .388 \\
\hline $2005-6$ & 1.571340 & 533.517 & 1.433 .317 & 671.140 & 2.104 .857 \\
\hline $2006-7$ & 1.604 .313 & 570.306 & 1.463 .314 & 711.305 & 2.174 .619 \\
\hline $2007-8$ & 1.621 .269 & 602.945 & 1.475 .525 & 748.689 & 2.224 .214 \\
\hline $2008-9$ & 1.615 .045 & 637.376 & 1.479 .550 & 772.871 & 2.252 .421 \\
\hline $2009-10$ & 1.604 .955 & 649.980 & 1.478 .355 & 776.580 & 2.254 .936 \\
\hline
\end{tabular}

FUENTE: Bravo Jáuregui, Luis. 12 años de educación en Venezuela (Escolaridad y alfabetización 1999-2010). P. 6.

http://www.venescopio.org.ve/web/wp-content/uploads/Informe-de-escolaridad-en-Vzla-1999-2011.pdf

Se aprecia un crecimiento moderado de este nivel y un equilibrio porcentual entre la atención en planteles privados y oficiales. Llama la atención la brecha que se aprecia entre los dos niveles, pero que parece cerrarse un poco entre el lapso escolar 2008 y 2009. Veamos finalmente el caso del comportamiento de la matrícula en el nivel de educación superior, ahora denominado por la Ley Orgánica de Educación de 2009, Educación Universitaria. Estas son las cifras entre 1998 y 2010.

45 http://www.venescopio.org.ve/web/wp-content/uploads/Informe-de-escolaridad-en-Vzla-1999-2011.pdf(07-04-2017) 
Matrícula de la Educación Universitaria/Antes Superior (Incluye Misión Sucre)

\begin{tabular}{|l|l|}
\hline Años escolares & Total \\
\hline $1998-9$ & 796.350 \\
\hline $1999-0$ & 818.438 \\
\hline $2000-1$ & 852.850 \\
\hline $2001-2$ & 881.501 \\
\hline $2002-3$ & 1.260 .855 \\
\hline $2003-4$ & 1.123 .063 \\
\hline $2004-5$ & 1.247 .714 \\
\hline $2005-6$ & 1.807 .122 \\
\hline $2006-7$ & 2.135 .146 \\
\hline $2007-8$ & 2.135 .000 \\
\hline
\end{tabular}

FUENTE: Bravo Jáuregui, Luis. 12 años de educación en Venezuela (Escolaridad y alfabetización 1999-2010), p. $6{ }^{46}$

En este cuadro se aprecia el crecimiento de la matrícula universitaria a partir de 2003, cuando se inicia la Misión Sucre.

Ahora bien, las políticas educativas hacia el sector universitario se inician en 2001 cuando el entonces Ministerio de Educación, Cultura y Deportes, dirigido por Héctor Navarro, a través del Viceministerio de Educación Superior, elabora el documento Políticas y Estrategias para el desarrollo de la Educación Superior en Venezuela 2000-2006. Este documento es de gran importancia para el periodo que hemos denominado de "Revolución Bolivariana" ya que con él se establecen las siguientes políticas a seguir en el sector: 1) Estructurar un sistema de educación superior (SES); 2) Elevar la calidad académica de las instituciones; 3) Mejorar la equidad en el acceso y desempeño estudiantil; 4) Lograr mayor pertinencia social de instituciones, programas y currículos; 5) Lograr una mayor interrelación institucional y 5) Promover la cooperación nacional, regional e internacional. ${ }^{47}$ En ese momento, la acción ejecutiva estaba dirigida a mejorar el sistema universitario existente, corrigiendo problemas como la calidad, la cobertura territorial y la equidad en el acceso a la educación superior. Sin embargo, con el tiempo el proceso político va tomando un rumbo ideológico diferente que repercute en las políticas educativas en general, pero muy especialmente, en el sector de la educación superior, por su importancia estratégica en la formación de profesionales para el país.

En ese mismo documento se señalan los desafíos que tienen que enfrentarse a futuro: 1.- Desdibujamiento de la diferenciación entre la misión y las funciones de las instituciones universitarias, las cuales deben responder a los "requerimientos diferenciados del desarrollo regional y nacional"; 2.- Desigualdad, en cantidad

46 http://www.venescopio.org.ve/web/wp-content/uploads/Informe-de-escolaridad-en-Vzla-1999-2011.pdf (07-04-2017)

47 Ministerio de Educación Cultura y Deportes. Políticas y Estrategias para el desarrollo de la Educación Superior en Venezuela 20002006. (Caracas: Edición del MECD. 2001), 41 y 42. 
y calidad, en la distribución regional de instituciones, carreras y matrícula; 3.Crecimiento escasamente controlado de las instituciones privadas; 4.- Progresivo deterioro de las instituciones públicas; 5 .- Cuestionada calidad de los estudios universitarios y falta de mecanismos de evaluación por parte del Estrado; 6.- Carencia de una visión del desempeño estudiantil; 7.- Orientación hacia la formación profesional aislada de las capacidades y actitudes humanísticas, intelectuales y éticas; 8.- Oferta de posgrados sin la debida acreditación y sin sustentación en procesos endógenos de investigación institucional y 9.- Predominio de organizaciones y prácticas curriculares rígidas y centradas en conocimientos atomizados y descontextualizados. ${ }^{48}$

A partir de 2002, el gobierno empieza a ejecutar sus primeras acciones estratégicas en el sector universitario. Veamos:

1) En enero de 2002 se crea el Ministerio de Educación Superior (MES) para asumir la dirección de la educación superior venezolana, la cual hasta ese momento era responsabilidad compartida entre el Ministerio de Educación, Cultura y Deportes (Viceministerio de Educación Superior) y el Consejo Nacional de Universidades (CNU), a través de la Oficina de Planificación del Sector Universitario(OPSU), según lo establecido por la Ley de Universidades - aún vigente - de 1970.

2) Como nuevo modelo de Universidad se crea en 2003 la Universidad Bolivariana de Venezuela (UBV). Su propósito inicial es ofrecer ingreso a todas aquellas personas que habían sido excluidas del sistema universitario tradicional (Universidades autónomas y universidades experimentales ${ }^{49}$ por el sistema de selección existente en el momento. En su aspecto curricular, la UBV se propone vincular la docencia y la investigación con el trabajo directo en la resolución de problemas de las comunidades en las cuales se encuentra la universidad y a partir de 2008, en la línea del Plan Nacional Simón Bolívar, se declara como una universidad socialista. ${ }^{50}$

3) Si bien para el 2000 y 2001 no estaba en el horizonte la creación de misiones para mejorar la equidad de acceso a la universidad, si existe la inquietud en el gobierno educativo de aumentar la cobertura, "propiciando que la educación impartida en las diversas regiones se realice: a) brindando oportunidades a las poblaciones más aisladas y de menores recursos. ${ }^{\prime 15}$ Esta política es la que se corresponde con la municipalización de la educación superior, que es el principio sobre el cual va a descansar la labor de Misión Sucre, creada en 2003. Esta Misión nace "como la estrategia para romper, por vía de la Educación Superior, los círculos de exclusión y consiste en incorporar a la Educación, antes que finalice el año 2004, a todos los bachilleres que así lo

\footnotetext{
$48 \quad$ Ibíd, 18 y ss.

49 Cf. Reinaldo Rojas. "Historia de la Universidad en Venezuela." Revista Historia de la Educación Latinoamericana.Publicación de la Sociedad de Historia de la Educación Latinoamericana (HISULA). Tunja-Colombia. no. 7, (2005), 73 y ss.

50 Cf. José Pascual Mora García. La Universidad venezolana a debate. (Caracas: Fondo Editorial IPASME. 2009), 50 y ss.

$51 \quad$ Ibíd. p. 49.
} 
deseen, de acuerdo a la Constitución (esto es, sin más limitaciones que las que se derivan de sus aptitudes, vocación y aspiraciones. ${ }^{152}$

4) Formación de un polo universitario socialista con la Misión Alma Máter, creada por el Ejecutivo en marzo de 2009 con el propósito de "impulsar la transformación de la educación universitaria venezolana y propulsar su articulación institucional y territorial, en función de las líneas estratégicas del Proyecto Nacional Simón Bolívar...". ${ }^{53}$

En este sentido, frente al sistema universitario existente, formado por universidades autónomas, experimentales, y privadas más los institutos y colegios universitarios, públicos y privados, la estrategia del nuevo gobierno es crear un sistema universitario bolivariano y socialista paralelo, dirigido desde el Ministerio de Educación Superior, para lo cual se anula la instancia participativa y de coordinación de políticas universitarias que constituía el Consejo Nacional de Universidades.

La Misión Alma Mater se transforma en la gran política de masificación de la educación superior venezolana, junto a la Misión Sucre. En cuanto a la primera, la meta es transformar los veintinueve (29) institutos tecnológicos y colegios universitarios oficiales en universidades; crear diecisiete (17) universidades territoriales; diez (10) universidades especializadas; dos (2) institutos especializados en educación; la Universidad Bolivariana de los Trabajadores "Jesús Rivero"; la Universidad de los Pueblos del Sur y los Complejos Universitarios Socialistas "Alma Mater" en las Aldeas Universitarias de Misión Sucre. ${ }^{54}$

Al hacer balance de estas políticas, la primera que requiere una evaluación cuanti-cualitativa es la Misión Sucre. De su papel en el nuevo sistema de educación superior, nos dice los siguiente Luis Bravo Jáuregui:

"Es el componente que infla los números del sistema educativo a partir del año 2003. Vale decir, que las misiones educativas son el factor que empuja al alza los indicadores del sistema educativo. Su crecimiento entre 2003 y 2007 define la ampliación de oportunidades educativas para las mayorías populares y, su disminución, marca un hito en la dinámica de la extraescolaridad, al producirse una caída espectacular de la contabilidad de la opción más popular de todas las que ha tenido el Estado venezolano." 55

Pasemos, ahora, a analizar las políticas llevadas a cabo al interior del sistema educativo superior, especialmente, en relación con la investigación y producción de conocimientos, como una de las Misiones de la Universidad.

52 Ministerio de Educación Superior. Misión Sucre. Compendio documental básico. (Caracas: Edición del MES - Ministerio de Salud. 2006), 26.

53 Ministerio del Poder Popular para la Educación Superior. Misión Alma Mater. Educación Universitaria Bolivariana y Socialista. Mora García (Caracas: Edición del MPPES. 2009), 3.

54 Ibid, 6.

55 http://www.venescopio.org.ve/web/wp-content/uploads/Informe-de-escolaridad-en-Vzla-1999-2011.pdf(08-04-2017) 


\section{Políticas públicas en la Educación Superior venezolana 2010-2016}

Las políticas públicas desarrolladas entre el 2010 y el 2016 en la Educación Superior ${ }^{56}$ complementanesta última parte del presente estudio.

El llamado milagro en educación que había significado el incremento de la matrícula escolar en la educación superior pronto se vio minimizada por las políticas que atacaron la productividad de conocimientos en las universidades oficiales, especialmente en las tres universidades que se disputaban el $50 \%$ de la productividad nacional, como veremos a continuación.

No cabe duda de que en las políticas educativas del Estado venezolano inicialmente hubo una propuesta innovadora, pero al mismo tiempo debemos alertar que fue una inclusión con crecimiento cuantitativo, pero no cualitativo; fue una inclusión que tenía por característica una mayor desigualdad, pues no se puede incluir incorporando otra exclusión, como lo es la ausencia de calidad. Esto se fue corroborando con el tiempo, pues ese perfil de crecimiento no se pudo sostener. Hoy las universidades lucen desoladas y los alumnos no pueden asistir, los que quedan; porque la mayoría han migrado forzosamente, algunos en condición de refugiados luego de las más de 100 muertes violentas acaecidas en las manifestaciones del año 2017. Otros, son desplazados o migrantes forzados; fuentes autorizadas informan sobre el estado en que se encuentra la matrícula en una de las dos primeras instituciones del ranking nacional, veamos: " en la Universidad de los Andes-Táchira, la deserción es un fenómeno que está afectando la matrícula, debido a que hay un abandono de las aulas (...) señaló que manejan un estimado aproximado de $45 \%$ de alumnos que abandonaron las aulas de la institución, lo que equivale a 3.500 estudiantes (...) la generación del futuro, que debe consolidarse académicamente, se está retirando para incorporarse a la economía informal o buscar alternativas laborales fuera del país. (...) Otra irregularidad que han observado en esta casa de estudios es que han aumentado las solicitudes de certificación de los programas y notas certificadas para ser utilizadas fuera del país. (...), lo más triste es que muchos profesionales, formados en calidad, se van del país a ejercer otras actividades.Entendemos la necesidad de cada estudiante, muchos se retiran para ayudar a sostener su hogar, porque el dinero no alcanza para la comida y mucho menos para pagar una residencia o el transporte." ${ }^{57}$ Por su parte la revista SIC, reconocida fuente de la Compañía de Jesús en Venezuela, nos aporta una serie de entrevistas sobre el estado actual de la matrícula en las universidades venezolanas; "la UCV, la Federación de Centros Universitarios calcula la deserción estudiantil en $30 \%$ y el nivel de abandono de los profesores en $15 \%$. En las universidades privadas se estima en 40 $\%$ el retiro del estudiantado.Robinson Rivas, director de la Escuela de Computación de la UCV, lamentó que la universidad se esté quedando sin docentes con estudios de tercer nivel: doctorados y especialistas, cuya experiencia es vital para mantener la excelencia

56 Aunque luego cambiaron de nombre a Educación Universitaria, en ese nominalismo exagerado.

57 Omar Pérez Díaz, actual director académico de la Universidad de Los Andes-Táchira nos señala sobre la crisis de la deserción escolar. https://lanacionweb.com/regional/se-agudiza-abandono-de-las-aulas-solo-10-egresa-de-bachillerato/ (Consultado 12-12-2017) 
educativa (...), para este nuevo semestre en la Escuela de Computación solo se inscribieron 700 alumnos de una plantilla original de 1.200 bachilleres; $y$ con respecto a los docentes ya se nos han ido 20 (...) La Universidad Simón Bolívar (USB) no escapa a esta realidad. Muchos de sus profesores se fueron a Perú, Ecuador y Brasil, a través de programas de formación. Pero, además del retiro de docentes que se van al exterior, esta casa de estudios debe enfrentar los problemas derivados de su ubicación en el Valle de Sartenejas, en Baruta, a donde cada vez es más difícil llegar por las fallas en el servicio de transporte (...). En las universidades privadas, el retiro de profesores y alumnos también mella la calidad educativa y la formación de nuevos profesionales." 58

No solo la crisis de la matrícula ha puesto a la universidad venezolana al borde del cierre, sino que los salarios de los profesores, reducidos a un valor aproximado de unos 4 dólares mensuales, son los más irresponsables que gobierno alguno pudiera otorgar a sus profesores. ${ }^{59}$ Por si fuera poco, las restricciones que sufren los presupuestos de investigación, los proyectos de investigación y los incentivos para fortalecer los grupos de investigación, no solo no alcanzan sino que resultan irrisorios frente a la escalada hiperinflacionaria; "Los exiguos financiamientos para los proyectos de investigación que puede ofrecer el CDCHTA ante el cerco presupuestario que han tenido las universidades en la última década, especialmente las autónomas. En un contexto de hiperinflación como el que vive el país, los financiamientos son simbólicos, insuficientes para alcanzar los objetivos de los proyectos. Estos financiamientos se ubicaban en julio de 2018 en menos de 3 USD para los proyectos de Grupo, que son los que reciben un monto más elevado." ${ }^{60}$ La población venezolana, en un país acostumbrado a recibir inmigrantes del mundo, sufre la más alta tasa de migración conocida en la historia ECONÓMICA de Venezuela. ${ }^{61}$

La filosofía política nos enseña que no se puede incluir en educación superior tutelando el pensamiento, es decir, amarrando la libertad de cátedra y la libertad de la investigación abierta. Las conquistas desde la reforma de Córdoba (1918) así lo han manifestado. No hay igualdad en un sistema democrático privando la libertad, es un principio de la justicia ineludible. ${ }^{62}$

En aras de la transparencia insertamos dos gráficos que muestran dos aciertos que no pudieron ser sostenidos en las políticas de Estado; uno, el incremento de la inclusión, y otro, la inversión en la educación superior. Exactamente a partir del año 2008 se iniciaron las restricciones en la inversión en Educación superior.

58 Robinson Rivas, de Universidad Central de Venezuela nos informa: "Universidades de Caracas se quedan sin alumnos y profesores por crisis económica."

http://revistasic.gumilla.org/2017/universidades-de-caracas-se-quedan-sin-alumnos-y-profesores-por-crisis-economica/ (Consultado 14 diciembre de 2017)

59 Leonardo Carvajal, de la Asamblea Nacional de Educación, y reconocido historiador de la educación nos apuntalaba ya en al año 2015 sobre la crisis salarial: "Leonardo Carvajal: No vale nada ser educador con esos niveles salariales", https://www.elimpulso. com/2015/09/03/leonardo-carvajal-no-vale-nada-ser-educador-con-esos-niveles-salariales/ (Consultado 12 de marzo 2017).

60 Alejandro Gutiérrez. "Breves notas sobre la crisis nacional y la investigación en la ULA", https://comoenboticadehumberto.blogspot. com/2018/07/notas-breves-sobre-la-investigacion-en.html. (Consultado 17 julio de 2018) Actualmente, es el coordinador del Consejo de Desarrollo Científico, Humanístico, Tecnológico y de las Artes (CDCHTA) de la Universidad de Los Andes (Venezuela).

61 Fernando Spiritto y Tomás Straka, coordinadores. La economía venezolana en el siglo XX. Perspectiva sectorial. Caracas: Instituto de Estudios Parlamentarios Fermín Toro, Universidad Católica Andrés Bello. 2018.

62 Michael J. Sandel, Justicia, ¿¿hacemos lo que debemos?, Bogotá: PenguinRandomHouse Grupo Editorial S.A.S., 2017. 


\section{MATRÍCULA ESTUDIANTIL EN EDUCACIÓN SUPERIOR 1986-2006}

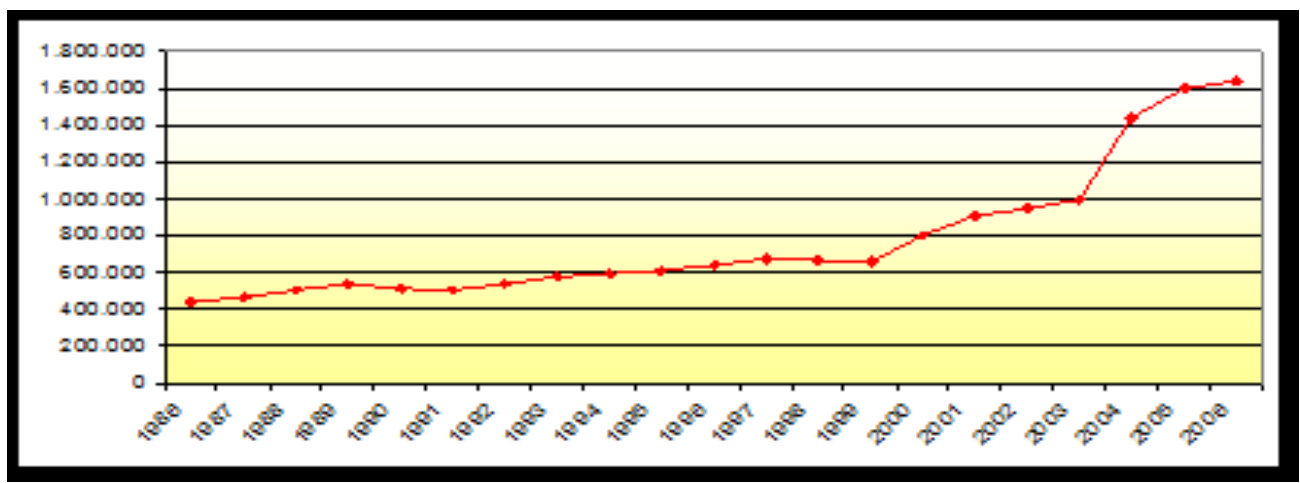

Fuente oficial. Ministerio de Educación Superior. $2007^{63}$

Inversión en Educación Superior en USS. Millones

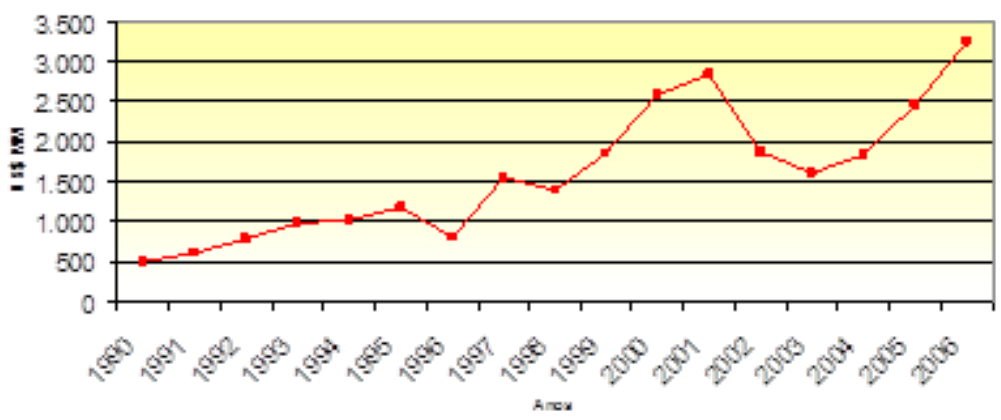

Fuente oficial: Ministerio de Educación Superior, 2007

Paradójicamente cuando más se diseñaron políticas de inclusión y se crearonfinalmente - casi 30 nuevas universidades, tambiénse diseñó por partida doble un plan estratégico para infravalorar las universidades públicas de alto impacto; simplemente por no estar sujetas al tutelaje académico. ${ }^{64} \mathrm{La}$ historia de la educación no es neutra y por eso consideramos que también debemos expresar la mirada crítica contra las políticas públicas que han desmontado el aparato de producción de conocimientos en la universidad venezolana; no es una mirada sesgada por criterios políticos partisditas que ha caracterizado la polarización política en Venezuela. Y decimos desmontado porque la crisis y falta de apoyo a la investigación han destruido buena parte del capital intelectual de los grupos

63 Fuente: Reinaldo Rojas. Conferencia en el Congreso de Universidades, Tamaulipas, México, 2007.

64 José Pascual Mora García. "La investigación tutelada en el CDCHTA-ULA" Educere, v.16 fasc. 53, ULA Mérida, 190 - 191, 2012 
de investigación e inducido a la fuga de talentos a otros países; hasta el punto que, De la Vega, un investigador del IVIC, comenta que "Venezuela es el principal emisor de personal altamente calificado e indicó que factores como la falta de competitividad de los salarios y la inseguridad son puntos determinantes al decidir dejar el territorio venezolano. De la Vega precisó que el $51 \%$ de los venezolanos que han ingresado a Estados Unidos son al menos licenciados, mientras que en el caso de España la cifra aumenta a 53\%, reseñó (...) que la emigración no forma parte de la cultura del venezolano, sin embargo, el deterioro de las condiciones generales del país ha favorecido que Venezuela se convierta en emisor de emigrantes cuando fue durante muchos años receptor. (...) casi dos millones de personas han emigrado de Venezuela." ${ }^{65}$

Lo cierto es que desde mediados de 2008 se buscó minar la productividad de los investigadores y las universidades, así como los programas que servían de visibilidad para la mostrar la calidad y excelencia de la productividad académica. La imposición del control del financiamiento tutelado por la Vicepresidencia de la República con el Decreto Presidencial № 6649. Este tutelaje dañó considerablemente la producción de conocimientos en la universidad al tener que pasar por su humillante autorización, como si fuera un organismo académico; destruyendo el desarrollo de la productividad en redes y el cosmopolitismo en las trayectorias de los investigadores; situación que fue minando las posibilidades ciertas de poder asistir a eventos internacionales. Con el argumento peregrino de que ser competitivos era apostar a los criterios burgueses de ciencia, y proponiendo una llamada masificación de la ciencia, que no llegó nunca.

Nuestra línea de investigación se inició en el año 1997 y hemos analizado a propósito de la fallida Ley de Educación Universitaria ${ }^{66}{ }^{6}$ n diciembre del año 2010, la Asamblea Nacional cometió un genocidio académico cuando se eliminó la data histórica de 20 años del Programa Sistema de Promoción al Investigador (SPI-PPI); programa que establecía el ranking de los investigadores reconocidos nacionalmente. A pesar de que había sido un programa exitoso, pues había experimentado un crecimiento positivo en sus casi 20 años, pasando de 741 investigadores (1990) a 6791 para el 2009; no obstante, se optó por eliminar el programa.

En enero de 2011 el Ministerio P. P. de Ciencia y Tecnología convocó a un nuevo Registro Nacional de Innovadores e Investigadores (RNII), pero los resultados habían menoscabado la tradición de la evaluación de la investigación generando inconformidad por el sesgo ideológico. Aun cuando en términos cuantitativos pareciera que hubo un crecimiento al incorporar los llamados "innovadores", lo cierto es que sirvió para aumentar estadísticas sin densidad. Ya que el nuevo sistema solo convalidó a los investigadores eméritos, pero dejó por fuera a los investigadores en los niveles I, II, III, y IV que habían hecho carrera por más de 20 años. Los resultados los estimamos como un crecimiento negativo

65 http://www.bancaynegocios.com/de-la-vega-casi-dos-millones-de-personas-han-emigrado-de-venezuela/ (Consultada 20 enero 2017)

66 José Pascual Mora García. “La Ley de Educación Universitaria-2010: en siete pares categoriales”, DikaiosyneNo 26, enero-junio 2011. 
en lo cualitativo, ${ }^{67}$ si tomamos en cuenta que una tercera parte de los anteriormente clasificados no aplicaron al PEII, además de una campaña de infravaloración hacia los investigadores destacados, que vieron cada vez más menguadas las posibilidades de hacer investigación de punta en nuestras universidades.

Las reducciones presupuestarias y limitaciones en las políticas de financiamiento de los programas de los Consejos de Desarrollo Científico Humanístico Tecnológico y de las Artes (CDCHTA) marcaron la pauta del declive de la productividad en la universidad venezolana llegando a ser cero el apoyo a programas de viajes al exterior y organización de congresos internacionales, el diferencial cambiario destruyó la opción real; al respecto Alejandro Gutiérrez del CDCHTA Universidad de Los Andes (ULA) nos apunta: "el retroceso que la actividad de investigación ha tenido en la universidad (...) ULA ha venido disminuyendo el número de proyectos de investigación financiados, el número de investigadores reconocidos por el Programa de Estímulo a la Investigación (PEI-ULA) desde 2013 y el número de Grupos de Investigación reconocidos y certificados por el Programa de Apoyo Directo a Grupos de Investigación (ADG) desde 2014." ${ }^{\prime 8}$ Afirmación que puede ser validada en el siguiente gráfico:

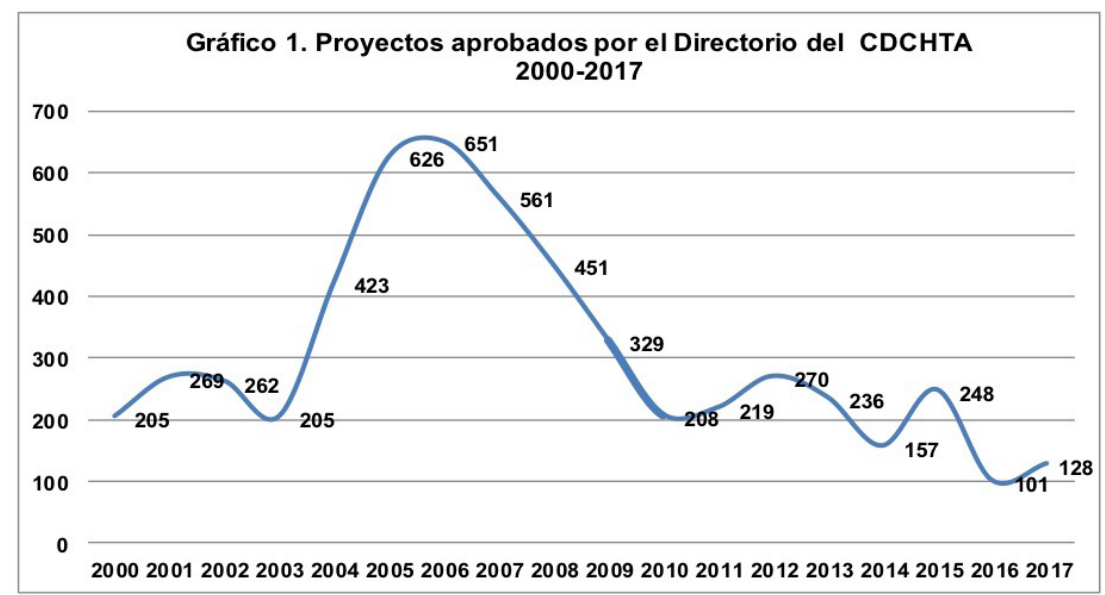

Fuente oficial: Alejandro Gutiérrez, Director del CDCHTA ULA

67 José Pascual Mora García. “El Crecimiento Negativo Cualitativo de los Investigadores." Fermentum, vol. 22 fasc.64 (2012), 255 - 273.

68 Alejandro Gutiérrez. "Breves notas sobre la crisis nacional y la investigación en la ULA", https://comoenboticadehumberto.blogspot. com/2018/07/notas-breves-sobre-la-investigacion-en.html. (Consultado 17 julio de 2018) 


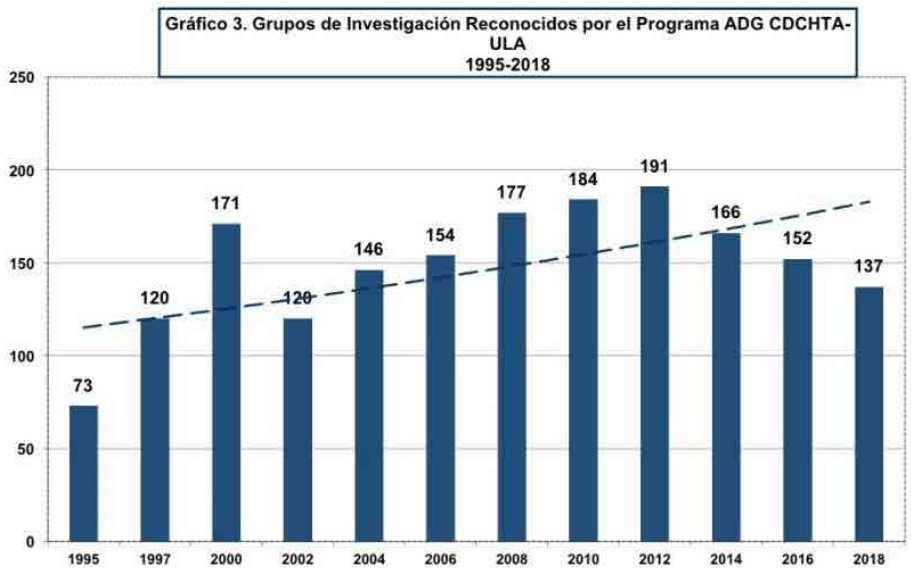

Fuente oficial: Alejandro Gutiérrez, Director del CDCHTA ULA

De esto se concluye que, si no hay universidad sin investigación, entonces estamos en presencia del atentado más grande contra el capital intelectual del país y, en consecuencia, no tenemos una universidad para hacerle frente a las exigencias del mundo anglobalizado. En un momento en el que sus pares latinoamericanos apuestan a la incorporación a los parámetros globales en materia de investigación, en Venezuela las políticas educativas de Estado están mirando al siglo XIX.

Al parecer este era el plan no solamente coyuntural sino estructural. Pues las amenazas se hicieron alarmantes cuando en la fallida Ley de Educación Universitaria (LEU-2010) se eliminaba prácticamente el rol de docente investigador autónomo para pasar a un modelo en donde el Estado ejerciera el tutelaje de la investigación en la universidad; en el Art. 28 se enunciaba que la investigación estaría bajo la responsabilidad de un ente denominado Consejo Territorial de Transformación Universitaria: “Cada Consejo Territorial de Transformación Universitaria tendrá un Centro de Estudios Territoriales definido como un espacio abierto académico-comunitario para la integración de saberes y conocimientos, que potencie la vinculación social y oriente la acción de las Instituciones Universitarias mediante la formación, la creación intelectual, la interacción con las comunidades y el desarrollo socioproductivo, en función de la concreción de redes de proyectos para el desarrollo integral del Eje Territorial correspondiente. En cada Centro de Estudios Territoriales, participarán los núcleos académicos de las instituciones de educación universitaria, las misiones, las organizaciones del Poder Popular, organismos y entes del Estado encargados de investigación, planificación y gestión de proyectos." ${ }^{\prime 69}$

La doble moral opera como mecanismo de acción. En teoría la LEU que había sido vetada, en la práctica se aplicaba subrepticiamente. Lo dramático fue que a

69 José Pascual Mora García. "La Ley de Educación Universitaria-2010, una mirada desde el punto de vista de la filosofía de la educación” EDUCERE Revista venezolana de Educación. Año XII, Nº 50, enero junio, (2012), 789-800. 
pesar del veto presidencial de la LEU-2010 se hizo una aplicación "blanda", lo cual no solo era inconstitucional sino inmoral;al estilo de Maquiavelo el "dedo del príncipe" ejercía su voluntad. En las universidades venezolanas losConsejo de Desarrollo Científico Humanístico Tecnológico y de las Artes (CDCHTA) administran la investigación y la decisión fue hacer una intervención "blanda" de las universidades tocando el sector más sensible como son los investigadores, y de esa manera la investigación pasó a estar mediatizada a las políticas y voluntad del mandatario de turno, en maridaje con las políticas interventoras; violentándose uno de los principios fundamentales de la investigación como es la investigación abierta. El derecho históricamente conquistado desde la reforma de Córdoba y que consagraba la Ley de Universidades fue menoscabado; inicialmente, se redujo el financiamiento de viajes al exterior a dos años (desde 2008), e incluso se introdujo una jurisprudencia para arrodillar a los investigadores ante la Vicepresidencia de la República, pues sin su autorización no se podría optar al beneficio; con el agravante de depositar en un ente ajeno a los pares académicos dicho arbitraje. Esa actitud controladora hizo que los investigadores fueran revisados en una base de datos del Estado, denominada "Lista Tascón" para controlar si los nombres de los mismos eran afectos al régimen o no. En 1998 los investigadores de nuestras universidades, con un barril de petróleo a 8 dólares, teníamos el derecho de poder participar en un congreso o foro internacional una vez al año, con apoyo de los respectivos Consejo de desarrollo Científico Humanístico y Tecnológico (CDCHT), previa demostración de la productividad académica, entre los periodos en los cuales se hacía la solicitud. Paradójicamente cuando más habíamos tenido ingresos petroleros menor fue el apoyo a los investigadores; veamos: en el año 99 subió a 12 dólares el barril, en el 2000 a 20 dólares, en el 2001 a 34, bajó en el 2002 a 30 dólares, en el 2003 subió a 34 dólares, en el 2004 subió a 38 dólares el barril petrolero; en el 2005 a 50 dólares, en el año 2006 a 60, en el año 2007 a 65 dólares, y en el año 2008 record histórico al vender el barril a 116,57 dólares.

Por otra parte, con el argumento del desarrollo de una supuesta ciencia endógena se limitó la participación de los investigadores reconocidos. Desconociéndose que necesariamente la ciencia se valida externamente, y sumándose el agravante de que son las redes internacionales las que en definitiva acreditan a los investigadores reconocidos de alto impacto.La participación de los investigadores en revistas indexadas en Scopus y el índice $h$ en Google Scholar se fue viendo mermado por las dificultades de publicación y los incentivos para actualizar conocimientos. ${ }^{70}$

En Venezuela el Sistema de Promoción al Investigador (SPI) fue desarrollado sobre la base del modelo mexicano en 1990. Y aunque había experimentado un

70 José Pascual Mora García. “El Crecimiento Negativo Cualitativo de los Investigadores," Fermentum: Revista Venezolana De Sociología y Antropología, vol. 22 fasc. 64 (2012): 255 - 273, 2012.

José Pascual Mora García. "La indexación de las revistas de educación e historia de la educación, un problema geopolítico, bioético y epistemológico" en Revista Suma-Paz, Revista Suma+Paz, Oficina de Postgrados, nro. 4, junio, Universidad de Cundinamarca. (2014): 39-50.

http://revistas_electronicas.unicundi.edu.co/index.php/Suma_paz 
crecimiento positivo en sus casi 20 años (1990-2010), pasando de 741 investigadores en 1990 a 6791 para el 2009, se optó por eliminar el programa. ${ }^{71}$ La Región Andina venezolana se ubicaba en el tercer lugar en el número de investigadores con 1299, luego de la Región Central y Zuliana. El Táchira había alcanzado 152 investigadores en 2009.

Por universidades se discriminaban los investigadores clasificados en el SPI -PPI hasta el 2009 de la siguiente manera: La Universidad del Zulia (LUZ) con 1322 investigadores; La Universidad de Los Andes (ULA) con 1094; y la Universidad Central de Venezuela (UCV) con 996, y entre las tres se distribuye el 50\% del total acreditado.

La gran contradicción es que, a pesar de su éxito, el programa fue intervenido y cerrado en 2010, por decisión de la Asamblea Nacional; institución que contaba con la mayoría absoluta del partido de turno.

Una referencia para señalar el éxito del programa nos la suministra Daissy Marcano (2007), entonces presidenta del Observatorio Nacional de Ciencia y Tecnología (ONCTI).Citamos la fuente oficial, en la que se muestra que incluso en términos de investigadores por habitantes se experimentaba un crecimiento, que nos ubicaba entre los países de América Latina con una proyección en ascenso por cada 10.000 habitantes.Venezuela reportaba para el año 2007, un total de 5222 investigadores reconocidos por el PPI: “En el período 90-98 la tasa de crecimiento promedio anual fue de 5,5\% y el crecimiento total del mismo periodo fue de 51,3\%. En el periodo 99-2005 la tasa de crecimiento promedio fue de 10,6\% y el crecimiento total del mismo período fue de 85,4\%."72Los cambios operados en el Sistema Nacional de Investigadores habían generado un balance positivo: "Estos resultados son consecuencia de los cambios en los criterios de evaluación realizados entre 2001 y 2002, proceso que se asumió luego de consultas y discusiones con la finalidad de cumplir efectivamente con el principal objetivo del programa, el cual es la promoción de la actividad científica y tecnológica en el país. Estos cambios mejoraron las condiciones de ingreso al Programa y aun cuando faltan algunos ajustes, algunos son de alta significación. Entre otros destacan el reconocimiento a la contribución que hacen los investigadores en la formación de nuevos investigadores, sobre todo para aquellos calificados en los niveles más altos del Programa. Así, para que una persona sea considerada como Investigador Nivel IV debe haber sido tutor de por lo menos cinco trabajos especiales de grado aprobados, o tesis de postgrado aprobadas, de las cuales al menos una debe corresponder a un doctorado. Los criterios de evaluación vigentes se hallan publicados en el portal del ONCTI (2007). "73 Los niveles estaban de la siguiente manera; se ingresaba Candidato, Nivel I, Nivel II, Nivel III, y Nivel IV, luego de varias convocatorias se optaba al nivel Emérito; "La creación del PPI estuvo muy influenciada por el Sistema Nacional de Investigadores (SNI) de México, instrumentado en ese país desde 1984. En

71 En nuestro trabajo seguimos en los criterios de Daissy Marcano y Mauricio Phelan. "Evolución y desarrollo del Programa de Promoción al Investigador en Venezuela", en Interciencia, vol. 34, no 1, (2009), 17-24.

72 Daissy Marcano y Mauricio Phelan. "Evolución y desarrollo del programa de promoción del investigador en Venezuela", INCI, vol.34, n.1, (2009): 017-024.

73 Ibíd. 
entrevista al, para entonces, Secretario Técnico (Medina, 1991) del PPI, este señalaba que "El PPI es una adaptación realizada por una comisión preparadora perteneciente al CONICIT, de lo que en México se denomina Sistema Nacional de Investigación. De hecho, al comparar el contenido del reglamento inicial del PPI con el del SNI, se encuentra que hay una gran similitud entre ellos.El PPI se ejecuta mediante convocatorias anuales. Los aspirantes son evaluados por pares constituidos en comisiones de áreas y clasificados en tres categorias: Candidato, Investigador y Emérito. La categoría de Investigador comprende cuatro niveles: I, II, III y IV, habiendo sido introducido este último nivel en la modificación estatutaria efectuada en el 2000."74 La diferencia es que el sistema mexicano ha podido revisarse en función del contexto sin eliminar la base de datos original, no tuvo esa misma suerte el sistema de investigación en Venezuela, a pesar de haber sido exitoso. Los criterios políticos-partidistas del Partido Socialista Unido de Venezuela (PSUV) pudieron más que los criterios académicos. Una muestra del éxito del programa se representa en la siguiente gráfica:

\section{Tasa De Crecimiento Promedio Anual 1990-2007}

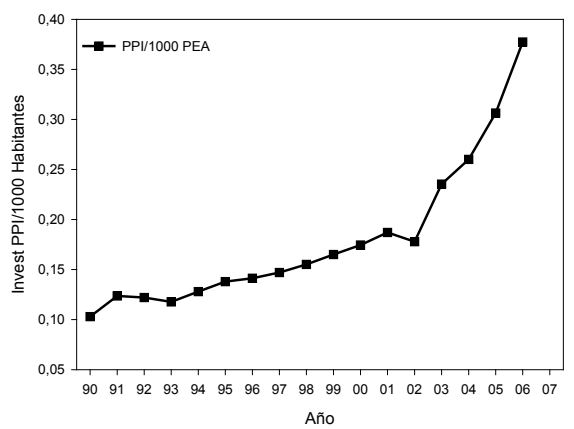

Fuente oficial: Marcano, $2007^{75}$

Los ajustes se hacían en el proceso, pero nunca eliminando el sistema anterior. Entre los méritos que se incorporaron fueron la validación de la formación de talentos, una variable que a nivel internacional era considerada fundamental. Igualmente, se amplió el reconocimiento a otros índices latinoamericanos, ya que hasta la fecha se le daba prioridad solo a Science Citation Index (SCI). En este sentido, las áreas humanísticas y sociales pudieron pasar a ser consideradas como publicación tipo A.Destacamos la importancia de esa inclusión, pues hemos sostenido que se incurre en una discriminación geopolítica, bioética y epistemológica al solo considerar índices anglosajones para la validación del conocimiento y la productividad de los investigadores en nuestros países latinoamericanos. ${ }^{76} \mathrm{En}$ nuestro caso hemos realizado estudios de indicadores bi-

\footnotetext{
74 Ibídem.

75 Daissy Marcano, presidenta del Observatorio Nacional de Ciencia y Tecnología (ONCTI), en el VII Congreso Iberoamericano de los Indicadores en Ciencia y Tecnología un balance a la comunidad internacional (Sao Paulo-Brasil, 2007).

76 José Pascual Mora García. “La indexación de las revistas de educación e historia de la educación, un problema geopolítico, bioético y
} 
bliométricos de los profesores de la Universidad de Los Andes, específicamente en el Núcleo Táchira, para determinar el sentido teleológico de los productos: dónde van los artículos, cuáles son, cuál es su impacto, quién, cuándo, y dónde pública, cuyos resultados fueron evaluados en la tesina doctoral presentada en la Universidad Rovira i Virgili, Tarragona- España. ${ }^{77}$ En el ámbito educativo venezolano se podía determinar la casi total ausencia de los estudios bibliométricos en el área humanística y social hasta el momento en que hicimos nuestro trabajo, dándosele prioridad a las llamadas ciencias duras; Arends (1974); Hebe (1986), y Curiel, (1999).

A nivel de América Latina, contamos con precedentes de análisis bibliométrico de la productividad de la Historia de la Educación a partir de las ponencias presentadas en los Congresos Iberoamericanos de Historia de la Educación, entre los que destacamos: Silvio Sánchez Gamboa (Universidad de Campignas-Brasil-1996) As Tendencias Teórico-Metodológicas Nos Congresos Ibero-Americanos de Historia da Educaçao; y del mismo autor. (1998) Historiografia da Educacçao $e$ Os Novos Campos Epistemologicos. Igualmente considerando el sentido amplio de los estudios bibliométricos podemos agregar 02 ponencias de Brasil: (01) José Carlos Souza Araujo et Al. (1996) Historia Da Educaçao Brasileira: Arquivos e FontesRegionals; (02) José Claudinei Lombardi e José Luis Sanfelice. (1996) Investigaçaoem Historia da Educaçao: O Grupo de Estudios e Pesquisas "Historia, Sociedade e Educaçao No Brasil". Agregamos también los trabajos realizados sobre la Red Sociedad de Historia de la Educación Latinoamericana:

Soto Arango, Diana. Estudios sobre historia de la Educación Latinoamericana de la Colonia a nuestros días. Bogotá, Universidad Pedagógica y Tecnológica de Colombia, RUDECOLOMBIA, 2.000. 351 p.

Soto Arango, Diana. (2008). “Revista Historia de la Educación Latinoamericana. Diez años convocando y liderando la investigación histórico-educativa en Latinoamérica". En Revista Historia de la Educación Latinoamericana, N 10. Tunja. UPTC.

Soto Arango, Diana. \& Bernal, Villate, Sandra Liliana. (2013). "Revista Historia de la Educación Latinoamericana, líder en la investigación histórico-educativa 1998-2013". Revista de la Educación Latinoamericana, vol. 15 no. 20. Tunja. UPTC.

Soto, Arango, Diana. (2010a). “Revista Historia de la Educación Latinoamericana. Trece años convocando y liderando la investigación histórico-educativa en Latinoamérica", En Revista RHELA, N 15, RUDECOLOMBIA: Tunja., UPTC p. 213 en donde se aborda un estudio cualitativo de la misma en sus 23 años. ${ }^{78}$

Y en los Congresos Internacionales de Historia de la Educación destacamos los dos Encuentros de las revistas realizados, el I Encuentro en Manizales, Co-

epistemológico" en Revista Suma-Paz, no. 4, junio, Universidad de Cundinamarca. (2014,) 39-50.

77 José Pascual Mora García. “Análisis bibliométrico de la productividad de los profesores en la Universidad de los Andes-Táchira, estudio de caso: área de historia de la educación, (1993-1998)”, edición Mimeografiada. 2000.

78 José Pascual Mora García, Diana Soto Arango, José Rubens Lima Jardilino. "La historia de la educación en América Latina: Contribución y aportes de la Sociedad de Historia de la Educación Latinoamericana SHELA (1994-2015)”. Revista História da Educação / HistoryEducationJournal, vol. 21, no. 51, (2017), 351- 375. 
lombia (2011) y el II Encuentro en Temuco, Chile (2018). ${ }^{79}$ En esta oportunidad se pudo presentar el estudio bibliométrico de la Revista RHELA, en donde se destaca que en los 30 números se han visibilizado educadores de 12 países:Argentina (4), Brasil (4), Cuba (2), Colombia (6), Chile (1), Ecuador (1), Guatemala (1), México (3), Perú (1), Puerto Rico (1), Uruguay (1), y Venezuela (4).El resumen histórico de RHELA se concentra en 30 números con más de 321 artículos de investigadores procedentes de 22 países, entre los que se destacan: Alemania, Argentina, Bolivia, Brasil, Colombia, Costa Rica, Cuba, Chile, Ecuador, España, El Salvador, Francia, Guatemala, Guinea Ecuatorial, Honduras, Inglaterra, México, Perú, Puerto Rico, Portugal, Uruguay y Venezuela.La Rhela se convierte en la referencia obligada de los investigadores de la Historia de la Educación Latinoamericana, por ser la versión más consolidada en presentar una mirada de la reciente validación de la categoría de la Internacionalización del Currículum, al demostrar que ha podido adelantarse a las necesidades competitivas actuales, apostando al liderazgo latinoamericano y delineando vertientes epistemológicas en el contexto global.

Lo cierto es que, según el balance oficial de la ONTIC, Venezuela se ubicaba entre los primeros 5 lugares de las publicaciones en SCI (2002-2006) registradas en América Latina: Brasil, México, Argentina, Chile, y Venezuela; tomando como referencia el ScienceCitationIndex (2007):

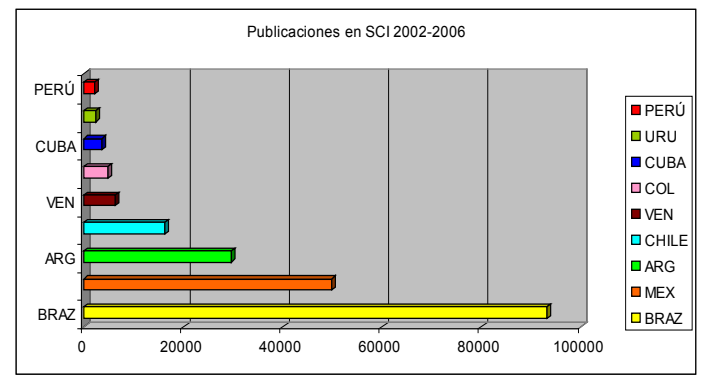

Fuente oficial: Daissy Marcano (2007)

Este dato es muy importante por cuanto nos permite ver en estado en que estábamos en el año 2007, y si lo comparamos con el actual, es abismal la diferencia. Ese logró fue cambiado radicalmente en los últimos 13 años, demostrándose el error que significó sacrificar los aportes a la investigación y el potenciar la productividad de alto impacto. Con todas las reservas que tenemos, pues consideramos que no son los únicos referentes en materia de calidad, es necesario estar en las estadísticas oficiales. El deterioro del posicionamiento de las universidades venezolanas en el ranking mundial es notable.

Aun cuando estábamos lejos,el índice de investigadores por cada 10.000 habitantes era aceptable para nuestro país para el año 2007. Si comparamos con

79 José Pascual Mora García y Sandra Liliana Bernal Villate. "La Revista Historia de la Educación Latinoamericana, (La génesis de un Paradigma Historiográfico en el siglo XXI), Ponencia en el II Encuentro de Revistas, en el XII Congreso Internacional SHELA, Temuco, 2018. 
los índices de algunos países de América Latina, Europa y Asia. Veamos: Chile tiene 5 investigadores por cada 10.000 habitantes; Brasil tiene 6 por cada 10.000 habitantes, España tiene 7 por cada 10.000 habitantes; Alemania tiene 32 por cada 10.000 habitantes; y Japón tiene 40 por cada 10.000 habitantes. Al respecto comenta Daissy Marcano: "Sin duda se puede concluir que el PPI ha contribuido de manera significativa al crecimiento del número de investigadores en las instituciones del país; sin embargo, solo se cuenta con 0,42 investigadores acreditados en el PPI por cada 10.000 habitantes de la población económicamente activa." 80

Orlando Albornoz ratifica nuestra tesis en su trabajo, al presentar la relación de documentos en el SCI en América Latina y el Caribe, 2007. ${ }^{81}$

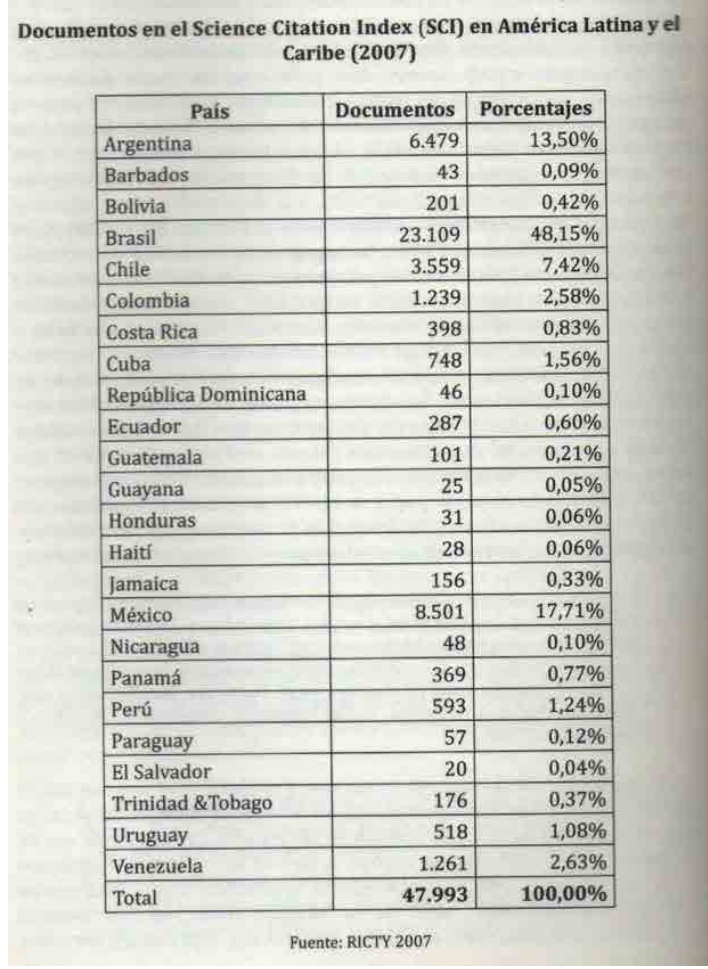

Luego de la eliminación del PPI en el año 2010, y tras la requisitoria del mundo académico se buscó enmendar el error histórico, que hemos denominado el genocidio académico. Fue así como apareció el nuevo programa de evaluación de los investigadores en Venezuela realizado entre marzo y junio de 2011 por parte de la ONCTI ${ }^{82}$ En la evaluación del nuevo PEII nacional (2011), lejos de

80 Daissy Marcano y Mauricio Phelan "Evolución y desarrollo del Programa de Promoción al Investigador en Venezuela", en Interciencia, Vol. 34, n 1,23, 2009.

81 Fuente: Documentos en SCI-2007, citado por Orlando Albornoz Las múltiples funciones de la universidad: crear, transferir y compartir conocimiento. San Cristóbal: Fondo editorial Simón Rodríguez, (2013)194.

82 Observatorio Nacional de Ciencia, Tecnología e Innovación (ONCTI) 
fomentar la investigación se evidenció una posición más ideologizada que académica en la modificación del programa anterior. Si para algo pudo servir el nuevo proceso de evaluación fue para legitimar el programa anterior, pues los resultados arrojaron cifras bastantes similares. Pero con el detrimento de un "genocidio académico" de más de dos mil quinientos investigadores que estando clasificados en el programa anterior, se negaron a participar en este como señal de protesta.

En efecto, el 15 de junio 2011 se publicaron los resultados preliminares del PEII nacional. De los 13.376 que aplicaron solo fueron clasificados 6.472 investigadores. ${ }^{83}$ En todo caso la eficiencia de la convocatoria al PEII es del $50 \%$. En el nivel formativo de los clasificados, el 53,3 \% tiene título de doctor. Por universidades el ranking es el siguiente: Universidad del Zulia (LUZ) 20\% (1256 investigadores); Universidad de Los Andes (ULA) 17\%, y Universidad Central de Venezuela (UCV) 13\%, lo que representa nuevamente un universo del $50 \%$ entre las tres instituciones.

Por niveles, la discriminación de los investigadores clasificados es: Nivel A: 4642 (que es el nivel inicial), Nivel B: 1801, y Nivel C: $307 .{ }^{84} \mathrm{El}$ SPI-PPI permitía ser el referente nacional de la metaevaluación de la calidad de la investigación de nuestras universidades, dando estímulo a los posgrados, a la conformación de grupos y centros de investigación, a la creación de redes académicas nacionales e internacionales, y propiciando incentivos a las publicaciones científicas en revistas indizadas nacionales e internacionales. Hoy el nuevo programa PEII no termina de consolidarse, y las dietas a los investigadores son irrisorias, pues no alcanzan materialmente para una comida.

La WEB del FONACIT-PEII señalaba en los datos definitivos del 28 de septiembre de 2011 que el total de investigadores e innovadores es "ocho mil setecientos treinta y ocho (8.738) aspirantes" discriminados de la siguiente manera: "un total de siete mil cuatrocientos setenta y siete (7.467) investigadores y doscientos sesenta y tres (263) innovadores." Los números por sí solos nos pueden confundir. Ante el aparente crecimiento cuantitativo yace un crecimiento negativo en lo cualitativo, pues una tercera parte de los investigadores del más alto nivel no aplicó, al considerar injusta la medida que anulaba al sistema anterior. Actuando irresponsablemente al no reconocer los compromisos con aquellos investigadores que tenían la dieta, en algunos casos, hasta el 2012.

83 Jaime Requena. Diario Tal Cual, 20 de junio de 2011.

84 Jaime Requena, Ciencia y poder, eco de sus conflictos. San Cristóbal. (Fondo Editorial Simón Rodríguez. San Cristóbal. 2011). 
El nuevo programa PEII instaurado recibió críticas $^{85}$ y sobre todo desestimó un trabajo de 20 años realizado con criterios de excelencia. El nuevo PEII quedó estigmatizado como una evaluación ideologizada, que no obstante ser objetiva -pues se aplicó un baremo - tiene el sesgo de la matriz ideológica que acompaña al programa. Aunque la ciencia nunca ha sido neutra (K. P. Feyerabend) era conveniente que se incluyera un equipo de evaluadores heterodoxo ideológicamente y de alto nivel según las clasificaciones de los niveles emérito y PPI IV del sistema anterior para darle mayor objetividad y credibilidad al nuevo programa; pues los evaluadores del PEII según Requena (2011) en su gran mayoría (62\%), nunca fueron Miembros Activos del extinto Programa de Promoción del Investigador (o PPI); y (51\%) de los evaluadores no lograron ingresar en su debida oportunidad al PPI, el resto (11\%), ni siquiera aplicaron al Programa, el Miembro de mayor jerarquía académica perteneció al Nivel III del PPI.

Finalmente, señalamos que lamentablemente se evidenció una vez más la presencia de la cultura balcánica y el criterio confesional de los grupos que profesan en el monopolio de la verdad de las políticas educativas del Estado venezolano. La universidad se nutre de la diferencia, y por eso fue un gran error buscar la unanimidad de opinión, ya que "la unanimidad de opinión puede ser apropiada para una iglesia, para las víctimas atemorizadas de algún mito (antiguo o moderno), o para débiles y dispuestos seguidores de algún tirano; la variedad de opiniones es una característica del espíritu objetivo; y un método que estimula la diversidad y es el único compatible con una perspectiva humanista." ${ }^{86}$ Obviamente el balance que presentamos aquí es preliminar, siempre la historia inmediata tiene sus limitaciones. Pero pensamos que hemos podido dejar ideas para el debate, más que conclusiones.

\section{CONCLUSIÓN}

No pretendemos cerrar el debate sobre un tema del dominio de la historia inmediata, pero arriesgarnos algunas ideas claves para la superación de un proceso que requiere de la reconstrucción del país.

1. Las políticas de Estado después de 1998 permitieron revertir el crecimiento negativo de la matrícula de la matrícula universidad, y a pesar de que había logrado duplicar la matrícula hasta el año 2008, se generó una con-

85 María Pilar García Gaudilla, "El PEI: negación de la Universidad autónoma y creadora en: http://presidencia.asovac.org/el-pei-negacion-de-la-universidad-autonoma-y-creadora/, consultado 20 de junio 2017

86 Karl P. Feyerabend (1975) Cómo ser un buen empirista: petición de tolerancia en asuntos epistemológicos, Nidditch, P. H. (Coord) Filosofía de la ciencia. México: Breviarios. F.C.E., p. 64 
tracción de la matrícula en los siguientes 10 años. Llegándose actualmente a tener una deserción que supera cifras alarmantes.

2. Después de haber alcanzado un posicionamiento como el 5to países de producción de paper's en América Latina según el SCI (2007), las políticas de Estado fueron reduciendo la posibilidad de participación a los investigadores. Lo cual liquidó casi por completo el capital intelectual de los principales centro de producción de conocimiento.

3. La eliminación del Sistema Nacional de investigación fue uno de los errores históricos mas significativos, un genocidio académico. No obstante, a pesar de que enmendó la falta creándose el Observatorio Nacional de Curncis, Tecnología e innovación (Oncti), nunca se pudo recuperar la eficacia y eficiencia del sistema anterior, además de sufrir un proceso de ideologización.

De esta manera se concluye, que el llamado milagro educativo de la revolución bolivariana terminó por ser la experiencia más trágica de la universidad venezolana, casi desde la epoca de la dictadura de Juan Vicente Gómez (1908-1935).

\section{REFERENCIAS}

Albornoz (2012) La Universidad ¿Reforma o experimento?; El discurso académico contemporáneo según las perspectivas de los organismos internacionales: los aprendizajes para la universidad venezolana y latinoamericana. Caracas: Instituto Internacional de la Unesco para la Educación Superior en América Latina y el Caribe.

Baptista, Asdrúbal y Bernard Mommer. El petróleo el en pensamiento económico venezolano. Caracas: Ediciones IESA. 1999.

Betancourt, Rómulo. Venezuela política y petróleo. Bogotá: Editorial Senderos. 1969.

Bonilla-Molina, Luis y Haiman El Troudi. Historia de la Revolución Bolivariana. Pequeña Crónica 1948-2004. Caracas: Ministerio de Comunicación e Información. 2004.

Bravo Jáuregui, Luis. La escuela venezolana. Educación de masas, politicas y resultados a partir de 1958. Caracas: Ediciones Episteme. 1999.

Bravo Jáuregui, Luis. 12 años de educación en Venezuela (Escolaridad y alfabetización 19992010). En: http://www.venescopio.org.ve/web/wp-content/uploads/Informe-de-escolaridad-en-Vzla-1999-2011.pdf

Comisión Presidencial para la Reforma del Estado (COPRE). Un proyecto educativo para la modernización y la democratización. Caracas: Ediciones de la COPRE. 1990.

Curiel, María Josefa, Contribución al Estudio de algunos Elementos de Bibliometría, en donde realiza un análisis bibliométrico de la producción bibliográfica de las investigaciones del IVIC en la década 1980-1989.Caracas: Escuela de Bibliotecología y Archivología de la Universidad Central de Venezuela, 1999.

Chávez, Hugo. El discurso de la Unidad. Caracas: Ediciones "Socialismo del siglo XXI". № 1, enero de 2007.

Dieterich, Heinz. Hugo Chávez y el Socialismo del siglo XXI. (6ª . Edición). Barquisimeto: Edición del Gobierno Revolucionario del estado Portuguesa. 2005.

Feyerabend, Karl P. Cómo ser un buen empirista: petición de tolerancia en asuntos epistemológicos, 
Nidditch, P. H. (Coord) Filosofía de la ciencia. México: Breviarios. F.C.E. 1975

Garrido, Alberto. Documentos de la Revolución Bolivariana. (2da. Edición) Mérida: Producciones Karol C. A. 2004.

Howard, Harrison Sabin. Rómulo Gallegos y la Revolución Burguesa en Venezuela. Caracas: Monte Ávila editores. 1976.

Márquez Rodríguez, Alexis. Doctrina y proceso de la educación en Venezuela. Caracas: Edición del autor. 1964.

Maldonado Veloza, Fabio. El proceso petrolero. Sus paradigmas kuhnianos. Mérida: Consejo de Publicaciones de la ULA: 1996.

Ministerio de Educación. Aportes para el debate sobre la Constituyente Educativa. Caracas: Publicación de la Dirección General Sectorial de Planificación y Presupuesto: Proyecto Constituyente Educativa. 1999.

Ministerio de Educación, Cultura y Deportes. Políticas y Estrategias para el desarrollo de la Educación Superior en Venezuela 2000-2006. Caracas: Edición del MECD. 2001.

Ministerio de Educación Superior. Misión Sucre. Compendio documental básico. Caracas: Edición del MES - Ministerio de Salud. 2006.

Ministerio del Poder Popular para la Educación Superior. Misión Alma Mater. Educación Universitaria Bolivariana y Socialista. Caracas: Edición del MPPES. 2009.

Marcano, Daissy y Mauricio Phelan. Evolución y desarrollo del programa de promoción del investigador en Venezuela. INCI, vol.34, n.1 (2009).

Mora García, José Pascual. La Universidad venezolana a debate. Caracas: Fondo Editorial IPASME. 2009

Mora García, José Pascual, "La Ley de Educación Universitaria-2010: en siete pares categoriales", Dikaiosyne, № 26, enero-junio 2011.

Mora García, José Pascual, “El Crecimiento Negativo Cualitativo de los Investigadores."Fermentum, vol. 22 fasc. 64, 2012.

Mora García, José Pascual, “La Ley de Educación Universitaria-2010, una mirada desde el punto de vista de la filosofía de la educación" Educere, Año XII, no 50, enero junio, (2011).

Mora García, José Pascual "La indexación de las revistas de educación e historia de la educación, un problema geopolítico, bioético y epistemológico" en Revista Suma-Paz, Revista Suma+Paz, Oficina de Postgrados, nro. 4, junio, (2014).

Mora García, José Pascual y Sandra Liliana Bernal, "Revista historia de la educación latinoamericana en los retos editoriales del siglo XXI." Inclusiones, volumen 5 - número 4 - octubre/diciembre (2018).

Prieto Figueroa, Luis Beltrán. El humanismo democrático y la educación. Caracas: Editorial Las Novedades. 1959.

Prieto Figueroa, Luis Beltrán. De una educación de castas a una educación de masas. (3ª . Edición) Caracas: Fondo Editorial IPASME. 2008.

Jaime Requena, Ciencia y poder, eco de sus conflictos. San Cristóbal. Fondo Editorial Simón Rodríguez. 2011.

República Bolivariana de Venezuela. Constitución de la República Bolivariana de Venezuela. En: http://www.minci.gob.ve/wp-content/uploads/2011/04/CONSTITUCION.pdf

Rojas, Reinaldo. “Historia de la Universidad en Venezuela." Revista Historia de la Educación Latinoamericana.Publicación de la Sociedad de Historia de la Educación Latinoamericana (HISULA). Tunja-Colombia. no. 7, (2005).

Rojas, Reinaldo. Universidad Centroccidental Lisandro Alvarado. Una historia de 50 años. Barquisimeto: UCLA, Ediciones del Rectorado). 2012.

Soto Arango, Diana. Estudios sobre historia de la Educación Latinoamericana de la Colonia a nuestros dìas. Bogotá, Universidad Pedagógica y Tecnológica de Colombia, RUDECOLOMBIA, 2000 
Soto Arango, Diana. "Revista Historia de la Educación Latinoamericana. Diez años convocando y liderando la investigación histórico-educativa en Latinoamérica". Revista Historia de la Educación Latinoamericana, no.10. (2008).

Soto Arango, Diana. \& Bernal, Villate, Sandra Liliana. "Revista Historia de la Educación Latinoamericana, líder en la investigación histórico-educativa 1998-2013". Revista de la Educación Latinoamericana, vol. 15 no. 20. (2013).

Soto, Arango, Diana. “Revista Historia de la Educación Latinoamericana. Trece años convocando y liderando la investigación histórico-educativa en Latinoamérica", En Revista de la Educación Latinoamericana no, 15, RUDECOLOMBIA: Tunja., UPTC (2010), p. 213.

Trigo, Pedro S. J. y otros. Una mirada sobre Venezuela. (Caracas: Fundación Centro Gumilla), 2008.

Uslar Pietri, Arturo. De una a otra Venezuela. Caracas: Monte Ávila editores. 1972.

Uslar Pietri, Arturo. Educar para Venezuela. Madrid: Editorial Lisbona. 1982.

Uslar Pietri, Arturo. (Coord.) Comisión Presidencial para el Estudio del Proyecto Nacional. Caracas: Presidencia de la Republica. 1986.

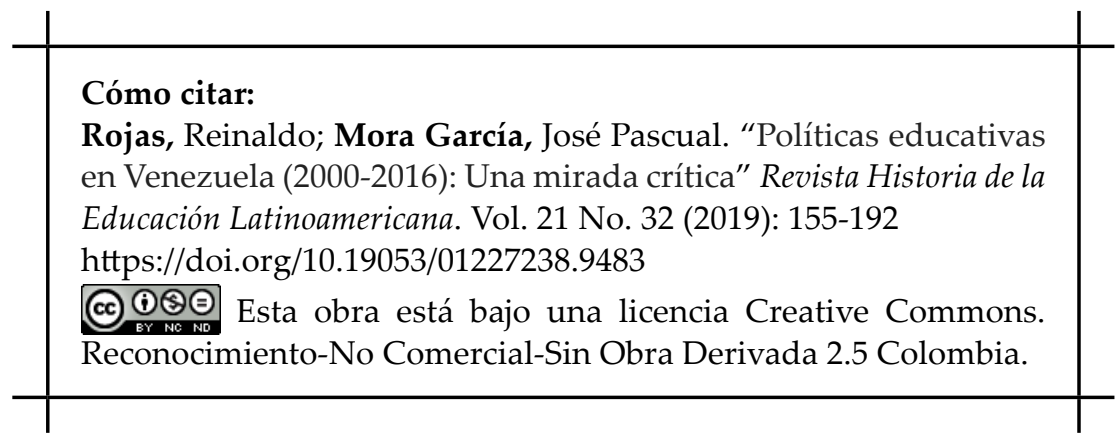

